NIST Technical Note 2005

\title{
Thermal Energy Storage for the NIST Net-Zero House Heat Pump
}

M. A. Kedzierski W. V. Payne H. M. Skye 


\title{
Thermal Energy Storage for the NIST Net-Zero House Heat Pump
}

\author{
M. A. Kedzierski \\ W. V. Payne \\ H. M. Skye \\ Energy and Environment Division \\ Engineering Laboratory
}

This publication is available free of charge from:

https://doi.org/10.6028/NIST.TN.2005

September 2018

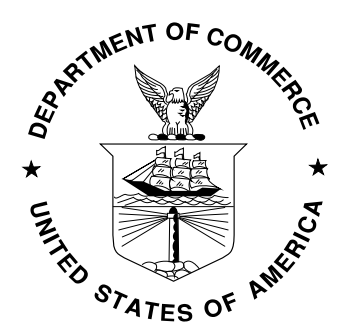

U.S. Department of Commerce Wilbur L. Ross Jr., Secretary

National Institute of Standards and Technology Walter Copan, NIST Director and Undersecretary of Commerce for Standards and Technology 
Certain commercial entities, equipment, or materials may be identified in this document in order to describe an experimental procedure or concept adequately. Such identification is not intended to imply recommendation or endorsement by the National Institute of Standards and Technology, nor is it intended to imply that the entities, materials, or equipment are necessarily the best available for the purpose.

National Institute of Standards and Technology Technical Note 2005 Natl. Inst. Stand. Technol. Tech. Note 2005, 46 pages (September 2018) CODEN: NTNOEF

This publication is available free of charge from: https://doi.org/10.6028/NIST.TN.2005 


\title{
Thermal Energy Storage for the NIST Net-Zero House Heat Pump
}

\author{
Mark. A. Kedzierski ${ }^{1}$ \\ W. Vance. Payne \\ Harrison. M. Skye \\ National Institute of Standards and Technology \\ Gaithersburg, MD 20899
}

\begin{abstract}
This report investigates the viability of thermal energy storage by using a phase-change material (PCM) for residential air-conditioning. The air-conditioning performance and the associated external and internal heat loads to the National Institute of Standards and Technology's Net-Zero Energy Residential Test Facility (NZERTF) were modelled for a single day near the summer solstice. The transient model predicted the frequency and the duration of the cooling cycles for the air-source heat pump with and without PCM. The model was used to examine two different PCM energy storage configurations for their efficacy in improving energy efficiency and/or in meeting the entire peak cooling load for the house. The first configuration limited the mass of the PCM to minimize the required changes to a conventional cooling system. The main component of the first type of cooling system was the integrated PCM evaporator, where a limited amount of PCM was made an integral part of the evaporator and placed within an annulus that surrounded the refrigerant tube. The system with the integral PCM evaporator showed no potential advantage over a conventional system with a larger evaporator and a smaller compressor. The system with the integral PCM evaporator also failed to deliver improved energy savings and peak load shifting due to insufficient amount of PCM and a significant resistance to heat transfer through the PCM within the annulus. In contrast, the second configuration for the residential cooling system, which used remotely stored PCM, exhibited significant energy savings while shifting the entire peak thermal building load to the PCM energy storage with minimal electricity used during the peak load. The remote PCM system achieved between a $6 \%$ and a $33 \%$ reduction in the required electrical energy for the entire cooling day, depending on the PCM thermal resistance, while maintaining acceptable indoor humidity ratios. The performance was best when the heat transfer resistance between the PCM and the evaporating refrigerant was minimized.
\end{abstract}

Keywords: air conditioning, energy storage, residential

\footnotetext{
${ }^{1}$ Corresponding author. Tel./fax: (301) 975-5282/(301) 975-8973. E-mail address: Mark.Kedzierski@ NIST.gov
} 


\section{TABLE OF CONTENTS}

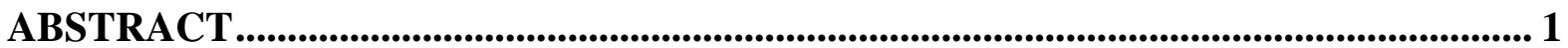

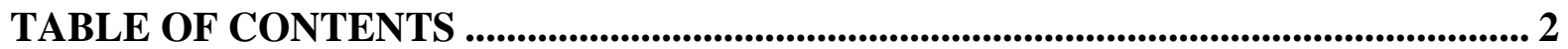

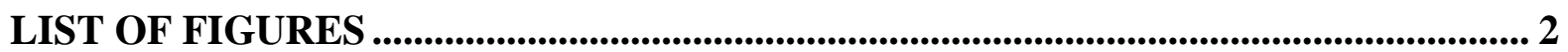

INTRODUCTION...................................................................................................................................... 3

MODELING BASE CASE ......................................................................................................... 4

MODELING WITH PCM ENERGY STORAGE .......................................................... 10

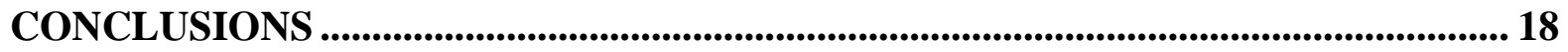

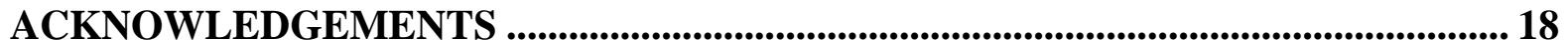

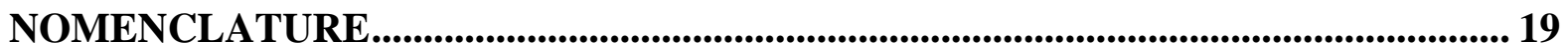

\section{LIST OF FIGURES}

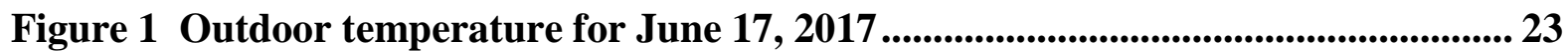

Figure 2 Energy balance for NZERTF .............................................................................. 24

Figure 3 Humidity ratio for the NZERTF on June 17, 2017 .......................................... 25

Figure 4 Plug loads for NZERTF on June 17, 2017 .................................................. 26

Figure 5 Solar heat gain on June 17, 2017 ....................................................................... 27

Figure 6 NZERTF air-source heat pump schematic (Davis et al., 2014) ......................... 28

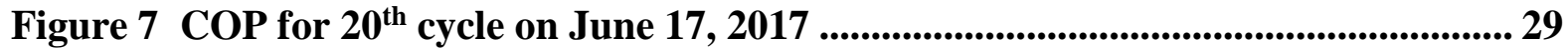

Figure 8 Comparison of measured COP to that predicted with eq. (3) for all 37

cycles............................................................................................................................................... 30

Figure 9 Comparison of measured compressor and fan work to that predicted with eq. (11) for all 37 cycles.................................................................................................. 31

Figure 10 Comparison of measured compressor and fan work that predicted with eq. (11) for 20th cycle on June 17, 2017 ......................................................... 32

Figure 11 Comparison of measured evaporator capacity to that predicted with eq. (12) for $20^{\text {th }}$ cycle on June 17, 2017 ........................................................................... 33

Figure 12 Measured evaporator capacity for all cycles of June 17, 2017 ........................ 34

Figure 13 Predicted evaporator capacity for all cycles of June 17, 2017 ........................ 35

Figure 14 Comparison of measured to predicted compressor run time for all cycle of June 17, 2017 ........................................................................................................ 36

Figure 15 Proposed PCM evaporator for investigation (Kedzierski et al., 2014) .......... 37

Figure 16 Shamsundar and Sparrow (1974) model for freezing and melting time for

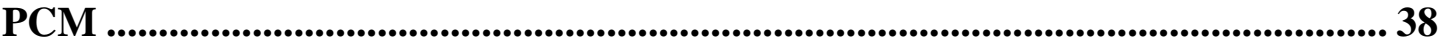

Figure 17 Indoor air temperature when using integrated PCM evaporator and 1 ton two-speed compressor

Figure 18 Indoor humidity ratio when using integrated PCM evaporator and 1 ton, two-speed compressor .............................................................................................................. 40

Figure 19 Schematic of remote PCM storage for residential air conditioning ............... 41

Figure 20 Effect of heat transfer resistance on required compressor and outdoor fan work for remote storage ................................................................................................... 42

Figure 21 Effect of heat transfer resistance on indoor humidity ratio when using remote PCM and 1 ton compressor 


\section{INTRODUCTION}

Using water as a phase-change material (PCM) is a popular way to provide air conditioning for large buildings. One benefit is that ice is made during the night when commercial electricity rates are significantly lower than during the day when the demand for electricity is high. In addition, chillers for making ice can be smaller than those sized to meet the building's immediate cooling demand because the smaller chillers can operate continuously throughout the night to make enough ice for the next day's peak use (ASHRAE, 2015). Residential electricity rates typically do not vary with the time of day, so making ice during the night has limited application for homes. However, ice storage can provide an alternative to exporting excess renewable electricity to the grid. As an example, the electricity produced by a wind turbine during the night could be used to power an ice-making machine for thermal storage. Ice made at night would be done at greater or comparable system efficiency due to lower outdoor air/condensing temperatures as compared to those during the day (ASHRAE, 2015). A home might have two separate systems for cooling: a relatively small chiller for making ice and a heat pump to meet the cooling demands when there is no stored ice. Work toward the realization of residential ice storage would benefit from ice heat transfer research. Pumping ice/water mixtures (ice slurries) or ice forming on coils are two potential research areas. Ice slurry and melt-ice-on-coil heat transfer studies like those done by Kumano et al. (2014) and Lo'pez-Navarro et al. (2013), respectively, would have to be either adapted or re-done for residential applications.

Measurements at the National Institute of Standards and Technology (NIST) net-zero energy residential test facility (NZERTF) ${ }^{2}$ shows that the air-source heat pump (ASHP) consumes approximately $45 \%$ - the largest share - of the home's total energy. Reducing this energy consumption is difficult because the efficiency of conventional ASHPs is nearing its practical limit due to intrinsic irreversibilities that cannot be mitigated. Nevertheless, energy savings remain achievable by increasing the cycle Coefficient of Performance (COP). One characteristic of the COP is that it decreases as the "lift," i.e., the difference between the indoor and outdoor air temperatures with which the ASHP work, increases. The lift is directly proportional to the space conditioning need, causing the heat pump to operate at a lower efficiency during the time when the building thermal load is greatest. These two factors are the major contributing causes of the electricity usage peak experienced by electrical utilities during the summer months. Air conditioning using thermal storage would contribute to the stability and reliability of utility power generation during the peak hours. Consequently, a non-conventional ASHP that enables residential load shifting and exceeds the current state-of-the-art COPs would be required to support to grid reliability.

A non-conventional, highly efficient, ASHP can be realized by using PCM-based Thermal Energy Storage (TES) during off peak times (Kedzierski, et al., 2014). In addition to increased efficiency, the PCM can be used for load shifting. Kedzierski et al. (2014) suggested that the key to realizing the efficiency improvements is to use PCM in conjunction with a compressor that is approximately half the size of a conventional system to meet a particular space-conditioning load. That report noted that the required size of the compressor would be reduced because the peak load would be met by the combined capacity of the mechanical air-conditioning and the melting of the PCM. It was further suggested that the daily efficiency would be improved because the unit runs nearly

\footnotetext{
${ }^{2}$ Referred to as the "house" for brevity and clarity in much of this manuscript.
} 
continuously instead of cycling on and off to meet the load, thus, avoiding a typical $2 \%$ to $8 \%$ loss in efficiency due to cycling (Baxter and Moyers 1985). Further efficiency improvements would be achieved because the PCM is recharged when the lift and the space-conditioning loads are the smallest. It was also proposed to use the stored energy to provide space conditioning during high lift conditions.

Kedzierski et al. (2014) identified three different conceptual designs for PCM storage with a residential (ASHP). The first design, "integrated PCM", directly coupled the PCM with the indoor tube-fin heat exchanger. This design benefits from simplicity, but it was expected to be somewhat limited by the amount of PCM that can be included within the heat exchanger volume and footprint. The second and the third designs used a "discrete PCM" configuration, which locates the PCM remotely in a storage tank. The second design used the ASHP working fluid (i.e. refrigerant) to deliver/remove energy to/from the remotely located PCM. The third design pumped the remotely stored PCM to a heat exchanger in the air handler. The drawbacks of the second and the third designs include increased complexity and additional components, which increase the cost and parasitic losses.

Models for the integrated and the discrete PCM configurations do not exist in the literature. The purpose of the present investigation is to model both the integrated and discrete PCM energy storage for use in air conditioning NIST's NZERTF. Accordingly, this paper determines the salient design parameters for an efficient and viable thermal energy storage using phase-change materials in a heat pump for net-zero homes.

\section{MODELING BASE CASE}

This section presents the model development and validation for predicting the house heat loads and the transient cooling performance of the NZERTF for June 17, 2017. The heat transferred through the house with and without a solar load was modeled along with the performance of the air-conditioning system. The cooling performance and the incident heat loads were modeled from existing measurements. The uncertainties for the measurements that were modelled in this study are taken from Davis et al. (2014) unless otherwise stated. All of the measurement uncertainties provided here are expanded uncertainties with a $95 \%$ confidence level (i.e., coverage factor of 2 ).

\section{House Loads for June 17, 2017}

A simplified approach was used to model the performance of the NZERTF air-conditioning system for a single high-load day that occurred near the summer solstice on June 17, 2017. The outdoor air temperature $\left(T_{\infty}\right)$, measured at the air intake for the outdoor condensing unit of the air conditioner, is shown in Fig. 1 as open circles. $T_{\infty}$ is plotted as a function of the time of day $(t)$ with a time of zero being midnight on June 16, 2017 and has an uncertainty of $\pm 0.7 \mathrm{~K}^{3}$. The solid line in Fig. 1 shows the fit of $T_{\infty}$ with respect to time that was developed for this analysis:

$$
T_{\infty}=4.28[\mathrm{~K}] \sin \left(7.32 \times 10^{-5}\left[\mathrm{~s}^{-1}\right](t-37102[\mathrm{~s}])\right)-298.72[\mathrm{~K}]
$$

Equation (1) is dimensional, with time having units of seconds and $T_{\infty}$ having units of Kelvin. The absolute, average difference between eq. (1) and the measured $T_{\infty}$ is approximately $\pm 1 \mathrm{~K}$. The

\footnotetext{
${ }^{3}$ All temperature measurements provided in this study have an uncertainty of $\pm 0.7 \mathrm{~K}$ and a confidence level of $95 \%$.
} 
form of eq. (1) was chosen solely because of its ability to replicate the measure outdoor temperature as a function of time.

The thermostat that controlled the on/off operation of the air-conditioning was set to maintain the indoor air temperature $\left(T_{\text {ai }}\right)$ of the house at approximately $297 \mathrm{~K}$. As a result of the difference between $T_{\text {ai }}$ and $T_{\infty}$, heat was transferred between the air inside the house and the outdoor air. This heat transfer $\left(q_{\mathrm{UA}}\right)$ was calculated as occurring independent of the solar sun load $\left(q_{\mathrm{s}}\right)$ of the house and was primarily governed by the combined conduction resistance through the walls, roof and windows, while neglecting heat transfer associated with air infiltration. An estimate for the average overall heat transfer coefficient through the walls, the roof and the windows (UA) can be written as a surface area weighted summation of the conduction heat transfer coefficients in parallel:

$$
U A=\frac{q_{\mathrm{UA}}}{\left(T_{\infty}-T_{\mathrm{ai}}\right)}=h_{\mathrm{w}} A_{\mathrm{w}}+h_{\mathrm{wN}} A_{\mathrm{wN}}+h_{\mathrm{r}} A_{\mathrm{r}}
$$

Here, the average conduction heat-transfer coefficients for the wall, the windows, and the roof $\left(h_{\mathrm{w}}\right.$, $h_{\mathrm{WN}}$, and $h_{\mathrm{r}}$, respectively) are taken as the reciprocal of the conductive resistances given in Pettit et al. (2015). Pettit et al. (2015) provided the composite conductive resistances (R-values) for the walls, the windows, and the roof as R-45, R-5.2, and R-72, respectively, which corresponds to heat-transfer coefficients of approximately $0.126 \mathrm{Wm}^{-2} \mathrm{~K}^{-1}, 0.109 \mathrm{Wm}^{-2} \mathrm{~K}^{-1}$, and $0.079 \mathrm{Wm}^{-2} \mathrm{~K}^{-1}$, respectively. The NZERTF construction mainly follows the "perfect wall" design concept (Lstiburek, 2010), which significantly reduces the effect thermal bridging caused by structural elements. Substitution of these heat transfer coefficients and the surface areas from Pettit et al. (2015), and provided in Fig. 2, gives the estimated $U A$ from eq. (2) as $90 \mathrm{WK}^{-1}$.

In contrast, the $U A$ obtained for the house, averaged over an eight-month period for mainly heating conditions by Omar et al. (2017), was $172 \mathrm{WK}^{-1}$. The larger $U A$ obtained by Omar et al. (2017) as compared to the value obtained from the R-values and eq. (2) may be due to the over estimation of the R-values for the windows in eq. (2) and the lack of inclusion of the heat transfer through the foundation of the house. These $U A$ values also differ from the $U A$ that was obtained in the present study for a single cooling day. That $U A$ value of $150 \mathrm{WK}^{-1}$ was obtained by trial and error such that the predicted cycles for the cooling heat load matched the duration and frequency of those measured in the morning hours when the solar load was not present. The difference between this cooling-estimated $U A$ and that obtained by Omar et al. (2017) is roughly $13 \%$. Omar et al. (2017) did show that their $U A$ was within $7 \mathrm{WK}^{-1}$ of a $U A$ obtained for the same heating measurements using a different method; however, no measurement uncertainty was provided that could be used to determine if $7 \mathrm{WK}^{-1}$ was within the uncertainty. One possible explanation for the difference between the present $U A\left(150 \mathrm{WK}^{-1}\right)$ and that obtained by Omar et al. (2017) is that neither method accounts for the heat recovery ventilator (HRV) which brings in cold outdoor air in the winter and hot outdoor air in the summer. The Omar et al. (2017) data contained all the winter months where the average temperature difference between the inside and the outside of the house was approximately $20 \mathrm{~K}$ as compared to an average temperature difference of roughly $2 \mathrm{~K}$ for the June 17 data. For the winter heating data, the $U A$ is associated with the loss of heat to the outside. Not accounting for the HRV caused the $U A$ to effectively increase in order to account for the additional cooling by the HRV in the winter. 
Figure 2 illustrates the transient energy balance on the total mass of moist air $\left(M_{\mathrm{a}}\right)$ in the house:

$$
E_{\mathrm{ST}}=M_{\mathrm{a}} c_{p_{\mathrm{a}}} \frac{\mathrm{d} T_{\mathrm{ai}}}{\mathrm{d} t}=q_{\mathrm{s}}+q_{\mathrm{g}}+q_{\mathrm{UA}}-q_{\mathrm{e}}
$$

The energy stored in the air $\left(E_{\mathrm{ST}}\right)$ is equal the product of the $M_{\mathrm{a}}$, the specific heat of the moist air $\left(c_{\mathrm{pa}}\right)$ and the rate of change of the indoor air temperature $\left(T_{\mathrm{ai}}\right)$ with respect to time $(t)$. Here $q_{\mathrm{e}}$ is the cooling heat load for the house air, which is a sum of the sensible $\left(q_{1 \phi}\right)$ and the latent heat $\left(q_{2 \phi}\right)$ loads. The symbol for the plug heat load is $q_{\mathrm{g}}$. The heat transferred by conduction through the walls, the windows, and the roof $\left(q_{\mathrm{UA}}\right)$ was calculated from eq. (2) and the temperature difference between the inside and outside air. The $q_{\mathrm{UA}}$ was negative when heat was transferred from the inside of the house to the outside in the morning hours when the outdoor temperature was less than the indoor temperature.

Use of eq. (3) implies the assumption that the house air is at uniform air temperature, which is generally not the case: measured temperature differences between rooms can be as much as $2 \mathrm{~K}$ (Omar, 2017). A model that accounts for the transient nonuniformity of the house air temperature would be computationally intensive and not expected to yield significantly more accurate results as compared to the present model that uses the "lumped capacitance" assumption for a uniform air-temperature distribution. The lumped capacitance assumption is appropriate for the present analysis because the resistance for heat transfer between the inside air and the outside air is significantly larger than the heat transfer resistance between the ASHP and the inside air (Incropera and DeWitt, 2002).

The humidity ratio is defined as the ratio of the mass of water vapor in the air to the mass of indoor dry air. Figure 3 shows the humidity ratio for the indoor conditioned air, which was calculated from the measured dew-point temperature of the return air to the evaporator with an uncertainty of $\pm 5 \%$. Direct local measurements of the humidity ratios were made. However, the humidity ratio obtained from the measured average air properties provided for a more representative average value than the average of the local humidity measurements. The latent load for the house was calculated from the derivative of the transient humidity ratio with respect to time $(\mathrm{d} w / \mathrm{d} t)$, the mass of dry air in the house, and the latent heat of vaporization of water $\left(i_{\mathrm{fg}}\right)$ as:

$$
q_{2 \phi}=M_{\mathrm{a}} \frac{\mathrm{d} w}{\mathrm{~d} t} i_{\mathrm{fg}}=1592.42\left[\mathrm{~W} \cdot \mathrm{K}^{-1}\right]\left(T_{\mathrm{d}}-T_{\mathrm{e}}\right)-5935.73[\mathrm{~W}]
$$

Using eq. (4), a linear fit of the $q_{2 \phi}$ was done with respect to the difference between the measured dew-point temperature of the air $\left(T_{\mathrm{d}}\right)$ and the measured surface temperature of the evaporator $\left(T_{\mathrm{e}}\right)$. The uncertainty of the fit shown in eq. (4) was roughly $\pm 10 \%$ of the predicted value. Figure 3 shows that the measured humidity ratios were less than 0.012 for more than $80 \%$ of the day while the setpoint temperature was satisfied, which is consistent with the requirements in ASHRAE Standard 55 (2017). 
The plug heat load $\left(q_{\mathrm{g}}\right)$ for June 17, 2017 is shown in Fig. 4 as a function of time where instantaneous spike loads were removed, and $q_{\mathrm{g}}$ was smoothed so that the total area under the curve remained approximately the same.

The solar irradiance $\left(I_{\mathrm{s}}\right)$ incident on the house on June 17, 2017 was measured with a flat-plate silicon pyranometer located on the ridge of the main roof to an uncertainty of $\pm 5 \%$. The solar heat gain $\left(q_{\mathrm{s}}\right)$ can be calculated from the $I_{\mathrm{s}}$ if the Solar Heat Gain Coefficient (SHGC) and the effective window area $\left(A_{\mathrm{WN}}\right)$ are known (Omar et al., 2017):

$$
q_{\mathrm{s}}=I_{\mathrm{s}} \operatorname{SHGC} A_{\mathrm{WN}}
$$

According to Pettit et al. (2015), the SHGC for the windows of the house is 0.25 , and the south facing window area is approximately $16.5 \mathrm{~m}^{2}$. A first estimate for the product of SHGC. $A_{\mathrm{wN}}$, assume that window blinds cover half of the windows, would be $2.06 \mathrm{~m}^{2}$. This is close to the final value that was used $\left(2.64 \mathrm{~m}^{2}\right)$, which was obtained by trial and error to give the best agreement between the measured and predicted duration, number, and time of the cooling cycles.

The solar heat gain $\left(q_{\mathrm{s}}\right)$ to the house was modeled during midday for times between $35000 \mathrm{~s}$ and 80000 s as:

$$
q_{\mathrm{s}}=2800[\mathrm{~W}] \sin \left(6.98 \times 10^{-5}\left[\mathrm{~s}^{-1}\right](t-35000[\mathrm{~s}])\right)
$$

For times outside of midday, i.e., $t<35000 \mathrm{~s}$ and $t>80000 \mathrm{~s}, q_{\mathrm{s}}$ was set to zero. The peak solar gain from eq. (6) occurred at $t=57500 \mathrm{~s}$ or 15:58:20 Daylight Saving Time (DST) (3:58:20 p.m.), which lags the peak incident solar radiation to the house as given by Omar (2017) on that day by approximately $10400 \mathrm{~s}\left(2.9 \mathrm{~h}\right.$ ). Figure 5 compares the $q_{\mathrm{s}}$ calculated from eq. (5) using $2.64 \mathrm{~m}^{2}$ for SHGC $\cdot A_{\mathrm{WN}}$ and the measured $I_{\mathrm{s}}(\mathrm{Omar}, 2017)$ to the $q_{\mathrm{s}}$ as predicted from eq. (6).

\section{Air-Source Heat Pump}

The instrumentation, data acquisition system, and measurement uncertainty associated with the R410A air-source heat pump, as well as all other electrical/mechanical systems within the NZERTF, are described in detail by Davis et al. (2014). Figure 6 shows a schematic of the heat pump and the location of the instrumentation. When the heat pump is operated in the airconditioning mode, the indoor unit contains the evaporator, which is identified as the indoor coil in Fig. 6. The cooling capacity, $q_{\mathrm{e}}$, is associated with this coil. The indoor unit is also shown to contain a fan that delivers the air from the house returns to the evaporator for cooling. The outdoor fan is not shown in Fig. 5. 
The $W_{\mathrm{c}}$ was the sum of the electrical work of the indoor fan the outdoor unit, which included the outdoor fan, the compressor, and controls. The Coefficient of Performance (COP) of the airconditioning unit was calculated from the measured evaporator heat duty $\left(q_{\mathrm{e}}\right)$ and the total electrical work input $\left(W_{\mathrm{c}}\right)$ as:

$$
\mathrm{COP}=\frac{q_{\mathrm{e}}}{W_{\mathrm{c}}}
$$

Figure 7 shows the COP for one of the 37 cycles that occurred during the observed day for the NZERTF ASHP. The time was set to zero at the moment the thermostat called for the compressor to activate for cooling of the house. The predicted COP is shown to increase from a value approaching zero (due to $q_{\mathrm{e}}$ approaching zero) at time zero to an approximate steady-state value after roughly $250 \mathrm{~s}$ of operation. The solid line in Fig. 7 shows the prediction of the COP that was made with the following fit of the measured COP:

$$
\begin{aligned}
& \mathrm{COP}_{\mathrm{p}}=B_{0}+\frac{B_{1} \tau}{t} \ln \left(\frac{t}{\tau}\right) \\
& \text { where } \\
& B_{0}=557.76-1009.09 \frac{T_{\infty}}{T_{\mathrm{e}}}+458.65\left(\frac{T_{\infty}}{T_{\mathrm{e}}}\right)^{2}
\end{aligned}
$$

Here, $\tau$ is the time constant equal to $0.95 \mathrm{~s}$. The average temperature of the evaporator tube surface is $T_{\mathrm{e}}$. For outdoor air temperatures that are greater than the indoor air temperature, the value of the $B_{1}$ is calculated as:

$$
B_{1}=40.80 \frac{T_{\infty}}{T_{\mathrm{e}}}-52.48
$$

For outdoor air temperatures that are less than the indoor air temperature, the value of the $B_{1}$ is calculated as:

$$
B_{1}=301.46 \frac{T_{\infty}}{T_{\mathrm{e}}}-329.78
$$

Equations (8) through (10) were built from an incremental fitting methodology that was developed for this project by the lead author. The derived constants would have to be refitted for other ASHP/house combinations.

Figure 8 compares the eq. (8) prediction to measured COP for all 37 cycles. Considering that the average cycle length was approximately $1500 \mathrm{~s}$, it is more important to predict the steady-state values of COP well than the startup values $(t<250 \mathrm{~s})$. Figure 8 shows that the steady-state COP values for $t>250 \mathrm{~s}$ (gray symbols) are predicted to within approximately $-8 \%$ and $+17 \%$. The average difference between measured and predicted COP was approximately $+1 \%$ showing that the predictions are roughly centered about the data for $t>250 \mathrm{~s}$. The approximately 50 negative values of COP that occurred out of 86,400 predicted by eq. (8) were set to zero. 
Figure 9 shows the sum of the measured compressor work and the indoor fan work for the NZERTF air conditioner for all 37 cycles versus the fitted $W_{\mathrm{c}}$ in watts as:

$$
W_{\mathrm{c}}=\left(12033 \frac{T_{\infty}}{T_{\mathrm{e}}}-11021\right)[\mathrm{W}]
$$

Figure 9 shows that the steady-state $W_{\mathrm{c}}$ values for $t>250 \mathrm{~s}$ are predicted to within approximately $-10 \%$ and $+7 \%$. The average difference between measured and predicted COP was approximately $+0.3 \%$ showing that the predictions are roughly centered about the data for $t>250 \mathrm{~s}$.

Figure 10 compares the measured compressor work to that predicted by eq. (11), using the measured $T_{\mathrm{e}}$ as a function of time. For $t>250 \mathrm{~s}$, the compressor work measurements are predicted to within $\pm 4 \%$ and are centered about the mean to within $0.1 \%$. For $t<250 \mathrm{~s}$, the compressor work measurements are predicted to within $-5 \%$ and $+7 \%$ and are centered about the mean to within $3 \%$.

The cooling capacity of the evaporator was calculated as a product of the work and the efficiency:

$$
q_{\mathrm{e}}=W_{\mathrm{c}} \mathrm{COP}
$$

Figure 11 compares the measured evaporator capacity for the twentieth cycle to that predicted by eq. (12), while using the measured $T_{\mathrm{e}}$ as a function of time. Overall, measurements for $t>250 \mathrm{~s}$ are predicted better than those for $t<250 \mathrm{~s}$. All the evaporator heat load measurements, for $t>250 \mathrm{~s}$, are predicted to within $-5 \%$ and $+10 \%$ and are centered about the mean to within $1.1 \%$. For $t<250 \mathrm{~s}$, approximately $72 \%$ of the evaporator heat load measurements are predicted to within $\pm 20 \%$ and are centered to within $10 \%$ of the prediction mean.

Figures 12 through 14 are used to demonstrate that the model can predict the magnitude, frequency, and duration of the measured evaporator capacity for June 17, 2017. Figure 12 provides the measured evaporator capacity as a function of time for the entire day, which comprised a total of 37 cycles to satisfy the cooling demand for the day. Figure 13 shows the predicted evaporator capacity also has 37 cooling cycles. Comparison between the cycle frequency given in Figs. 12 and 13 shows that both measured and predicted have 10 full cycles before the $10 \mathrm{~h}$ mark. In addition, these early cycles exhibit a predicted and measured peak capacity of approximately $6200 \mathrm{~W}$ due to the low outdoor temperature. For time greater than $10 \mathrm{~h}$, the evaporator peak capacity is roughly $5900 \mathrm{~W}$ for both measured and predicted capacity. For the entire day, the total measured evaporator capacity was approximately $64192 \mathrm{Wh}$, which is within $5 \%$ of the predicted value of $61365 \mathrm{Wh}$. The total measured and predicted sensible loads for the day were within $3 \%$ of each other, approximately $45612 \mathrm{Wh}$ and $44298 \mathrm{Wh}$, respectively. The sensible heat was $71 \%$ and $72 \%$ of the total cooling load for the measurements and predictions, respectively. The total measured and predicted latent loads for the day were approximately $18580 \mathrm{Wh}$ and $17067 \mathrm{Wh}$, respectively. The total measured and predicted compressor electrical energy (and outdoor fan) for 
the day were within $1.5 \%$ of each other being approximately $19378 \mathrm{Wh}$ and $19632 \mathrm{Wh}$, respectively.

Figure 14 compares the measured to the predicted compressor run time $\left(t_{\mathrm{c}}\right)$ for each numbered cycle $\left(n_{\mathrm{c}}\right)$. The figure shows that 20 out of the 37 cycle run times are predicted to within $200 \mathrm{~s}$. Nearly half of the remaining run times are predicted to within $400 \mathrm{~s}$.

\section{MODELING WITH PCM ENERGY STORAGE}

The previous section presented and validated the model for predicting the transient cooling performance of the NZERTF for June 17, 2017. This section discusses how that model was modified in order to predict how PCM energy storage would affect the cooling performance of the NZERTF. This section examines three different PCM energy storage concepts: integrated PCM, remote PCM, and remote PCM with PCM liquid-line subcooling.

\section{Integrated PCM}

Figure 15 shows the proposed integrated PCM evaporator that was analyzed. The PCM evaporator resembles a conventional residential evaporator in that it is a tube-and-plate-fin geometry with air flowing between the aluminum plate fins and evaporating refrigerant flowing inside nominally $9 \mathrm{~mm}$ OD copper tubes. The refrigerant tubes are inside larger copper tubes thus forming annuli that are filled with PCM (integrated PCM). The total tubing length was set to double $(140.8 \mathrm{~m})$ that of the existing evaporator to provide for a larger mass of PCM while keeping the size of the evaporator small enough to realistically fit within typical residential indoor air-handlers. For the same reason, the outer diameter of the evaporator tube that contained the PCM was chosen to be $0.0254 \mathrm{~m}$. This configuration gives a total mass of PCM of approximately $53.65 \mathrm{~kg}$. The melting temperature of the PCM was chosen to be at the average evaporator temperature of the base case evaporator. Consequently, the average refrigerant temperature of the evaporator, while it is freezing the PCM, was chosen to be $5 \mathrm{~K}$ less than the PCM phase-change temperature $\left(T_{\mathrm{pe}}=282\right.$ $\mathrm{K})$. The PCM does not flow in the annulus, rather, each tube is closed on both ends. The specific heat of the solid PCM and the thermal conductivity of the solid PCM at the freezing temperature were $1380 \mathrm{~J} \cdot \mathrm{kg}^{-1} \mathrm{~K}^{-1}$, and $1.09 \mathrm{~W} \cdot \mathrm{m}^{-1} \mathrm{~K}^{-1}$, respectively.

The main limiting factor for the integral PCM design is the thickness of the annulus. The annulus thickness controls? the resistance to heat transfer for freezing the PCM and also the heat transfer resistance for melting the PCM to achieve cooling. Consequently, the smaller the annulus space is, the smaller the heat transfer resistance of the PCM. However, the capacity for energy storage is reduced as the annulus space is reduced. The rest time between cycles dictates the annulus space because freezing the PCM is a transient process. Shamsundar and Sparrow (1974) developed an analytical solution for this transient heat transfer problem. Equation (13) shows their solution for the time $(t)$ to freeze based on a dimensionless radius, $\eta=r / r_{\mathrm{o}}$ :

$t=\frac{\frac{1}{2}\left(1-\eta^{2}\right)+\frac{1}{2}\left(1-\eta^{2} \sqrt{1-4 \operatorname{Ste} \ln \eta}\right)+\sqrt{2 \operatorname{Ste}} \frac{\sqrt{\pi}}{4} \exp \left(\frac{1}{2 \text { Ste }}\right)\left\{\operatorname{erf}\left(\sqrt{\frac{1}{2 \text { Ste }}-2 \ln \eta}\right)-\operatorname{erf}\left(\sqrt{\frac{1}{2 \text { Ste }}}\right)\right\}}{2 q_{\mathrm{o}}^{\prime \prime} /\left(\lambda_{\mathrm{p}} \rho_{\mathrm{p}} r_{\mathrm{o}}\right)}$ 
Equation (13) is valid for constant heat flux $\left(q_{\mathrm{o}}^{\prime \prime}\right)$ evaluated at the outer radius of the tube $\left(r_{o}\right)$. The Stefan number (Ste) is defined in the Nomenclature section and is evaluated using the solid phase PCM properties. The solid density $\left(\rho_{\mathrm{p}}\right)$ and the latent heat of melting $\left(\lambda_{\mathrm{p}}\right)$ of the PCM are shown in the denominator of eq. (13), and are equal to $1715 \mathrm{~kg} \cdot \mathrm{m}^{-3}$ and $192600 \mathrm{~J} \cdot \mathrm{kg}^{-1}$, respectively.

The PCM analysis provided by Shamsundar and Sparrows (1974) was one of the few explicit solutions for cylindrical coordinates available in the literature. Because of the limited number of references, eq. (13) does not share all of the conditions of the present problem for the integral heat exchanger. For example, eq. (13) is valid for a constant heat flux applied to the outer tube for the freezing application. This is due to the constant heat flux boundary condition at the outer wall as being given as a function of Fourier's law for conduction in the solid. Conversely, the integral heat exchanger is designed for a heat flux at the inner tube when freezing and a heat flux at the outer tube when melting. Given that the preliminary nature of the present investigation, the solution does not have to be exceedingly precise; it only needs to provide reasonable predictions. With this in mind, Fig. 16 plots eq. (13) for $r_{\mathrm{o}}$ of $6.5 \mathrm{~mm}$ and four different solid phase PCM thermal conductivities $\left(k_{\mathrm{p}}\right): 1.09 \mathrm{Wm}^{-1} \mathrm{~K}^{-1}, 10 \mathrm{Wm}^{-1} \mathrm{~K}^{-1}, 100 \mathrm{Wm}^{-1} \mathrm{~K}^{-1}$, and $1000 \mathrm{Wm}^{-1} \mathrm{~K}^{-1}$ to investigate the importance of the conduction boundary condition. The reasoning is that a larger thermal conductivity would represent increased heat transfer at the wall as would be present for natural convection through a melting liquid.

As Fig. 16 shows, the solutions for freezing times are all indistinguishable from each other (within $2 \%$ ) despite a variation in thermal conductivity of three orders. Consequently, this result suggests that, according to eq. (13), a wide variation in the magnitude of single-phase heat transfer is not important in determining the freezing time. Further confirmation of this conclusion is the plot in Fig. 16 for a specific heat $\left(c_{\mathrm{p}}\right)$ of zero, which corresponds to only latent heat exchange occurring in the cylinder, lies within $2 \%$ of (nearly coincides with) the predictions for $c_{\mathrm{p}}=1380 \mathrm{~J}_{\mathrm{kg}} \mathrm{kg}^{-1} \mathrm{~K}^{-1}$. For the case of only latent heat exchange, Shamsundar and Sparrows (1974) give the time for total freezing, which can be rewritten in terms of total PCM mass $\left(M_{\mathrm{p}}\right)$ and total evaporator capacity as:

$$
t_{\mathrm{m}}=\frac{M_{\mathrm{p}} \lambda_{\mathrm{p}}}{q_{\mathrm{e}}}
$$

For the annulus geometry given in Fig. 16 and a total evaporator tubing length of $140.8 \mathrm{~m}$, the total $M_{\mathrm{p}}$ is roughly $16.4 \mathrm{~kg}$. With this mass and a nominal evaporator capacity $\left(q_{\mathrm{en}}\right)$ of approximately $4500 \mathrm{~W}$ (roughly 1.5 tons), eq. (14) gives a total time for freezing of approximately $700 \mathrm{~s}$, which roughly agrees with that provided by Fig. 16. Considering that eq. (14) agrees with eq. (13) and that a large variation in single-phase heat transfer properties causes an average variation in the eq. (13) results of $1 \%$, and considering that eq. (13) does not depend on the initial PCM temperature, it can be concluded that eq. (13) only accounts for the latent heat exchange in the PCM. For this reason, a simple lumped capacitance transient heat transfer analysis was done to estimate the order of the time required for single-phase heat transfer, which was roughly $20 \mathrm{~s}$ for a $5 \mathrm{~K}$ temperature change in the PCM, i.e., approximately $3 \%$.

The PCM evaporator was modeled for three different modes of operation. First, the PCM evaporator was modeled for the case of the evaporating refrigerant being used to freeze the PCM 
during times that cooling was not called for by the thermostat. The second case was when the frozen PCM was used for cooling while the compressor was off. For this case, the PCM was assigned a nominal heat duty of $q_{\mathrm{en}}$. The third case that was modeled was when the evaporating refrigerant cooled the air while the PCM was liquid. Predictions were made for both the heat duty and the mass of frozen PCM.

For the first and second PCM modes, because the annulus had a fixed mass of PCM, the mass of frozen PCM was modeled by modeling the time remaining for the PCM to completely thaw $\left(t_{t}\right)$ :

$$
t_{\mathrm{t}}=t_{\mathrm{c}}\left(1-f_{1 \phi}\right) \frac{q_{\mathrm{e}}}{q_{\mathrm{en}}}
$$

If the PCM were frozen at the same rate as it was used to cool, and if none of the $q_{\mathrm{e}}$ were required for single phase heat transfer to the PCM (all cooling capacity went to freezing the PCM), then the time to thaw would be equal to the total compressor run time: $t_{\mathrm{t}}=t_{\mathrm{c}}$. This not being the case, eq. (15) required two correction factors to account for these effects. The fraction of total heat transfer that goes to single phase heat transfer was accounted for with $f_{1 \phi}$. For the annulus shown in Fig.16, $f_{1 \phi}$ was set to 0.04 , which came from the sum of the $1 \%$ difference exhibited between the zero and the non-zero heat capacity eq. (13) solution and the $3 \%$ difference between the eq. (13) solution and the single-phase-heat-transfer-lumped-capacitance approximation. The ratio $q_{\mathrm{e}} / q_{\mathrm{en}}$ was used to account for the PCM freezing occurring at $q_{\mathrm{e}}$ rather than the nominal heat flux $\left(q_{\mathrm{en}}\right)$. Equation (12) was used to calculate the $q_{\mathrm{e}}$ based on the outdoor temperature and a $5 \mathrm{~K}$ lower evaporator temperature that was required to freeze the PCM.

The total PCM cooling duty $\left(q_{\mathrm{p}}\right)$ was the sum of the sensible cooling $\left(q_{\mathrm{ps}}\right)$ and the latent cooling $\left(q_{\mathrm{pl}}\right)$. The $\left(q_{\mathrm{p}}\right)$ was the sum of the sensible cooling $\left(q_{\mathrm{ps}}\right)$ when the evaporator temperature was less than the air temperature $\left(T_{\mathrm{a}}\right)$ and the dew-point temperature $\left(T_{\mathrm{d}}\right)$, respectively. The sensible cooling load was calculated for $t_{\mathrm{t}}>0$ (when frozen PCM is available) from:

$$
q_{\mathrm{ps}}=506\left[\mathrm{~W} \cdot \mathrm{K}^{-1}\right]\left(T_{\mathrm{a}}-\frac{1}{2}\left(T_{\mathrm{w}}+T_{\mathrm{d}}\right)\right)
$$

The leading constant shown in eq (16) was obtained from the sensible heat transfer $h A$ of the base case. This was done to ensure the same sensible heat transfer characteristics as the base case, which is equivalent to adjusting the airflow rate until the same sensible behavior is achieved. The sensitivity of the leading constant was analyzed by increasing it in steps of roughly $500 \mathrm{WK}^{-1}$ up to $4500 \mathrm{WK}^{-1}$, which did not change the total heat load for the day by more than $1 \%$.

The latent cooling load was calculated for $t_{\mathrm{t}}>0$ from eq. (4) as:

$$
q_{\mathrm{pl}}=1592.42\left[\mathrm{~W} \cdot \mathrm{K}^{-1}\right]\left(T_{\mathrm{d}}-T_{\mathrm{e}}\right)-5935.73[\mathrm{~W}]
$$

where the wall temperature of the evaporator $\left(T_{\mathrm{e}}\right)$ was derived from a simple cylindrical conduction model as: 


$$
T_{\mathrm{e}}=\frac{\left(-\frac{0.6 T_{\mathrm{ps}} \pi L_{\mathrm{e}} k_{\mathrm{p}}}{\ln \left(\frac{r_{\mathrm{p}}}{r_{\mathrm{o}}}\right)}+1592.42\left[\mathrm{~W} \cdot \mathrm{K}^{-1}\right] T_{\mathrm{d}}-5935.73[\mathrm{~W}]\right)}{1592.42-\frac{0.6 \pi L_{\mathrm{e}} k_{\mathrm{p}}}{\ln \left(\frac{r_{\mathrm{p}}}{r_{\mathrm{o}}}\right)}}
$$

Equation (18) considers the temperature drop that occurs from the phase-change interface radius $\left(r_{\mathrm{p}}\right)$ to the outer radius $\left(r_{\mathrm{o}}\right)$ of the PCM. Equation (18) is a conservative estimate because the subcooling of the PCM is neglected, whereas, the frozen PCM is assumed to be at the melting temperature $\left(T_{\mathrm{ps}}\right)$.

The air-side latent cooling load $\left(q_{1}\right)$ while the compressor was running with no PCM cooling load was calculated for $t_{\mathrm{t}}<0$ from an energy balance as:

$$
q_{1}=1592.42\left[\mathrm{~W} \cdot \mathrm{K}^{-1}\right]\left(T_{\mathrm{d}}-T_{\mathrm{ps}}-\Delta T_{\mathrm{p}} \frac{\ln \left(\sqrt{f_{\mathrm{p}}\left(1-\left(r_{\mathrm{i}} / r_{\mathrm{o}}\right)^{2}\right)+\left(r_{\mathrm{i}} / r_{\mathrm{o}}\right)^{2}}\right)}{\ln \left(r_{\mathrm{i}} / r_{\mathrm{o}}\right)}\right)-5935.73[\mathrm{~W}]
$$

$f_{\mathrm{p}}$ is the fraction of the total PCM mass that is frozen in annulus. Equation (17) accounts for the additional resistance to heat transfer due to the presence of the PCM in the annulus.

While the PCM was used to cool, the system work was set equal to the indoor fan work of $125 \mathrm{~W}$ because during this time the compressor was off.

For the third mode of heat exchange with the PCM evaporator, the cooling duty $\left(q_{\mathrm{ec}}\right)$ was reduced due to the heat transfer resistance through the liquid PCM within the annulus as:

$$
q_{\mathrm{ec}}=q_{\mathrm{e}} \frac{\left(T_{\mathrm{st}}-T_{\mathrm{e}}\right)}{\left(T_{\mathrm{st}}-T_{\mathrm{e}}+\Delta T_{\mathrm{p}}\right)}
$$

where $T_{\mathrm{st}}$ was the setpoint temperature of the thermostat. The value of $q_{\mathrm{e}}$ was calculated from eq. (12). The temperature drop across the PCM annulus $\left(\Delta T_{\mathrm{p}}\right)$ was calculated with a steady-state conduction model. The average temperature of the evaporator at the outer refrigerant tube wall $\left(T_{\mathrm{e}}\right)$ was set to the average measured value of $282.2 \mathrm{~K}$. The average evaporator temperature for this case was increased only if the system was unable to satisfy the setpoint temperature. 
The latent cooling heat duty with the evaporating refrigerant when the PCM was liquid was reduced for the case of the evaporator having PCM within the annulus due to the higher surface temperature, which was larger by $\Delta T_{\mathrm{p}}$ :

$$
q_{2 \phi}=1592.42\left[\mathrm{~W} \cdot \mathrm{K}^{-1}\right]\left(T_{\mathrm{d}}-T_{\mathrm{e}}-\Delta T_{\mathrm{p}}\right)-5935.73[\mathrm{~W}]
$$

For fixed evaporator surface area, Park et al. (2001) have shown that the efficiency of a residential $\mathrm{AC}$ increases approximately linearly as the compressor frequency $(\omega)$ is reduced from $90 \mathrm{~Hz}$ to 30 Hz. For example, the efficiency was shown to increase by approximately $36 \%$ when the compressor frequency was reduced from $60 \mathrm{~Hz}$ to $30 \mathrm{~Hz}$. The improved system performance $\left(\mathrm{COP}_{\mathrm{I}}\right)$ associated with an effectively smaller nominal compressor tonnage, which was obtained from the Park et al. (2001) measurements, were fitted to the baseline COP and their respective frequencies as:

$$
\mathrm{COP}_{\mathrm{I}}=\mathrm{COP}\left((1+K)-K \frac{\omega_{\mathrm{I}}}{\omega}\right)
$$

where the constant $K$ is equal to 0.722 and 1.696 for base compressor frequencies $(\omega)$ of $60 \mathrm{~Hz}$ and $90 \mathrm{~Hz}$, respectively. To reproduce the Park et al. (2001) data, the base COP for eq. (20) is approximately 3.6 and 2.3 for a $\omega$ of $60 \mathrm{~Hz}$ and $90 \mathrm{~Hz}$, respectively.

If the purpose of eq. (20) was merely to reproduce the Park et al. (2001) measurements, then COPI would have simply been a linear function of $\omega_{\mathrm{I}}$, with the baseline COP and $\omega$ being omitted from the fit. Using ratios of the system performances and ratios of the frequencies in eq. (20), allowed the frequency ratio to be replaced by the nominal tonnage ratio of the compressors, i.e., $\omega_{\mathrm{r}} / \omega=$ $N_{\mathrm{I}} / N$. In this way, the efficiency of the NZERTF could be adjusted to account for reduced compressor tonnage without being bound to the absolute value of the Park et al. (2001) system performance. In addition, the form of eq. (20) allows the comparison of two different performance enhancements by comparing the results for two different values of $K$. The smaller value of $K$ approximates the improvement in the system performance by reducing only the compressor size while fixing the size of the evaporator. The larger value of $K$ approximates the improvement in system performance for simultaneous reduction of the compressor size and doubling of the evaporator surface area. ${ }^{4}$ This is the case for the integrated PCM where in addition to operating at a lower compressor tonnage, the PCM evaporator has double the heat transfer surface area of that of the base case. Corresponding to the larger $K$, both effects act to improve the efficiency as compared to the base case.

The base case system efficiency (COP) that was used in eq. (20) was taken from eq. (8). The system performance of the PCM system was calculated from eq. (20) by using the appropriate nominal compressor tonnage ratio. The PCM system used a two-speed compressor to take advantage of the larger system efficiencies at lower outdoor temperatures. During non-peak times, a $50 \%$ larger compressor tonnage was used when the system was used to freeze the PCM.

\footnotetext{
${ }^{4}$ The latent load is calculated based on the average surface temperature of the evaporator.
} 
Figure 17 shows the house air temperature as a function of time of day while using the PCM evaporator described above and a 1 ton, two-speed compressor for two different values of $K$. The solid line and the dashed line represent $K$ values of 1.696 and 0.722 , respectively. The choice of the 1 ton compressor was a compromise between meeting the peak load of the day and increasing the efficiency as a consequence of longer run times. For $K=1.696$, the figure shows that the compressor experienced 29 run cycles, which is approximately a $22 \%$ reduction as compared to the base case (37 cycles), and that the integrated PCM evaporator system satisfied the setpoint temperature throughout the day. Conversely, for $K=0.722$, the integrated PCM evaporator system was unable to meet the setpoint temperature between $13.9 \mathrm{~h}$ and $22.2 \mathrm{~h}$ where the setpoint was exceeded by approximately $3 \mathrm{~K}$, and during a peak of $300.5 \mathrm{~K}$ near $19 \mathrm{~h}$. For the entire day, the total measured evaporator capacity was approximately $60913 \mathrm{Wh}(K=1.696)$ and $57883 \mathrm{Wh}(K$ $=0.722$ ), which was approximately $1 \%$ and $6 \%$ less, respectively, than the base case with the 2 ton compressor and no PCM. The total sensible load for the day was within $1 \%$ and $6 \%$ of the base case being approximately $44204 \mathrm{Wh}(K=1.696)$ and $41479 \mathrm{Wh}(K=0.722)$, respectively. The total latent loads for the integrated evaporator was within $3 \%$ and $4 \%$ of the base case being approximately $16544 \mathrm{Wh}(K=1.696)$ and $16437 \mathrm{Wh}(K=0.722)$, respectively. The integrated PCM evaporator roughly offered a $37 \%(K=1.696)$ and a $26 \%(K=0.722)$ energy savings over the base case. The total system energy values for the day with the integrated PCM evaporator with $K=1.696$ and $K=0.722$ were approximately $12320 \mathrm{Wh}$ and $14515 \mathrm{Wh}$, respectively.

Figure 18 shows that the indoor humidity ratio (a partial indicator of thermal comfort) produced by the integrated PCM system, while assuming a $K=1.696$, was acceptable because the humidity ratio was less than 0.012 and the temperature was within the setpoint for most of the day. As compared to humidity ratio for the base case shown in Fig. 2, the humidity ratio produced by the integrated PCM evaporator with $K=1.696$ is roughly $6 \%$ larger. The larger humidity ratio is due to the higher evaporator surface temperatures caused by the thermal resistance of the PCM. This effect could be reduced by designing a system that operated at a lower phase-change temperture; however, the lower PCM temperature would necessitate greater system energy input. For the lower system efficiency $(K=0.722)$, Fig. 18 shows that the humidity ratio is approximately the same as that of the higher efficiency system $(K=1.696)$ except during peak hours where the PCM has been spent and the compressor is not large enough to meet the load.

Table 1 Effect of PCM mass on system performance

\begin{tabular}{|c|c|c|c|c|c|c|c|}
\hline$r_{\mathrm{o}}(\mathrm{mm})$ & $K$ & $M_{\mathrm{p}}(\mathrm{kg})$ & $t_{\mathrm{m}}(\mathrm{s})$ & $\begin{array}{c}\text { Sensible } \\
(\mathrm{Wh})\end{array}$ & $\begin{array}{c}\text { Latent } \\
(\mathrm{Wh})\end{array}$ & $\begin{array}{c}\text { Total } \\
\text { work } \\
(\mathrm{Wh})\end{array}$ & $\begin{array}{c}\text { Peak } T_{\mathrm{a}} \\
(\mathrm{K})\end{array}$ \\
\hline 4.45 & 0.722 & 0 & 0 & 42162 & 17394 & 13030 & 299.6 \\
\hline 4.45 & 1.696 & 0 & 0 & 44259 & 17170 & 10528 & 297.5 \\
\hline 5.00 & 1.696 & 3.6 & 231 & 44290 & 16905 & 10862 & 297.5 \\
\hline 6.47 & 0.722 & 16.4 & 1052 & 41479 & 16436 & 14515 & 300.5 \\
\hline 6.47 & 1.696 & 16.4 & 1052 & 44204 & 16543 & 12320 & 297.5 \\
\hline 8.00 & 1.696 & 33.2 & 2131 & 44214 & 16522 & 13263 & 297.5 \\
\hline 9.00 & 1.696 & 46.0 & 2959 & 44039 & 16099 & 13569 & 297.5 \\
\hline 10.00 & 1.696 & 60.5 & 3884 & 44061 & 16253 & 13656 & 297.5 \\
\hline 12.7 & 1.696 & 107.0 & 6869 & 43722 & 15539 & 13851 & 298.0 \\
\hline
\end{tabular}


Table 1 illustrates the effect of PCM mass $\left(M_{\mathrm{p}}\right)$ within the evaporator by varying the outer radius $\left(r_{\mathrm{o}}\right)$ of the evaporator tube. For the same $K$, each simulation shown in Table 1 exhibited similar latent and sensible heat transfer characteristics. The last column shows the maximum indoor air temperature experienced during peak cooling times, where a value of 297.5 indicates that the systems satisfied the indoor air temperature setpoint throughout the day. In general, the analysis shows that because of the heat transfer resistance through the PCM, adding more PCM in order to achieve increased energy storage results in increased work input and therefore reduced energy efficiency. In fact, the $K=1.696$ systems with the best performances are the two with the smallest PCM masses: $3.6 \mathrm{~kg}$ and $0 \mathrm{~kg}$. These systems have $44 \%$ and $46 \%$ less energy input requirements than the base 2 ton system. The humidity ratios for both the $3.6 \mathrm{~kg}$ and the $0 \mathrm{~kg}$ PCM system remain mainly below 0.012 during the peak hours while maintaining the indoor air temperature within the setpoint limits. Consequently, for the current integrated PCM evaporator system design, there is no advantage over a high-efficiency system without a PCM that achieves the high efficiency by means of a 1 ton compressor and a doubling of the evaporator heat transfer surface area. There are two reasons for this result. First, the system without PCM requires approximately $3 \%$ system work to meet the same heat transfer loads, indoor air temperatures, and humidity ratios. Second, because the integrated PCM evaporator has no frozen PCM during the peak load hours due to insufficient PCM mass in the annulus, there is minumal peak load shifting. As Table 1 shows, increasing $r_{\mathrm{o}}$ and the PCM mass acts to increase the system power requirements with an insufficient increase in the time of frozen PCM use $\left(t_{\mathrm{m}}\right)$ during the peak hours. In addition, without the added effect of increased system effciency due to the larger evaporators (systems with $K=0.722$ ), the indoor air temperature does not remain within the bounds of the setpoint. From the above analysis, the present integrated PCM evaporator design is not a viable candidate for residential energy storage due to the significant temperature gradients across the PCM in the annulus and the lack of sufficient PCM mass to accomplish meaningful load shifting during peak hours. To further emphasise that the integrated PCM evaporator as modelled provides no benefit, Table 1 shows that more energy savings can be obtained by increasing the size of the evaporator without the use of PCM while simultaneously reducing the size of the compressor.

\section{Discrete PCM}

To mitigate the effect of insufficient PCM mass, a second concept for the PCM evaporator locates the PCM external to the air handler within its own heat exchanger (discrete PCM) as shown in Fig. 19. Storing the PCM external to the evaporator eliminates the concern of having sufficient PCM mass within a limited evaporator volume and footprint, but adds complexity as additional valves are needed for control. Clarksean (2006) built and tested a mockup/benchtop apparatus to test the concept of a PCM slurry to reduce residential air-conditioning peak loads. Clarksean (2006) demonstrated that a PCM could be either cooled or heated and then pumped to a heat exchanger to cool or heat air in a residential-like duct. Consequently, remote PCM air conditioning could be achieved by pumping a PCM slurry. The advantage of such a configuration is that it avoids the resistive heat transfer irreversibilities associated with using a secondary fluid. Further efficiency losses could be avoided by using an immiscible, low vapor-pressure PCM in conjunction with direct contact heat exchange between the refrigerant and the PCM.

In order to meet the NZERTF peak load cooling demand with only the PCM heat exchanger, it was necessary to use approximately $935 \mathrm{~kg}$ of PCM storage. This value was obtained iteratively 
with the discrete PCM analysis by observing the mass of PCM that was required to meet the entire peak load. Using only the PCM to cool during peak hours, with the compressor turned off, provides two key advantages over a conventional air-conditioning system. First, the system efficiency is improved as compared to the base case because of the increase in the evaporator size and because the PCM is frozen during off peak hours when the outdoor temperature is at its lowest of the day. Second, only the blower power is used during peak hours, so that the electric utility receives the benefit of load shedding. A two-speed system allows the compressor to be operated at high speed while the PCM is being frozen and low speed while the indoor air is being cooled during off-peak hours. The higher speed is used because not enough PCM could be frozen to meet the peak load cooling with a single-speed, one-ton compressor.

The choice of the PCM system design determines the magnitude of the heat transfer irreversibilities associated with charging (freezing) the PCM, and it determines the heat transfer irreversibilities associated with transferring the cooling from the PCM to the air. Rather than choosing a specific remote PCM system to model, the heat transfer resistance was varied to simulate different remote PCM systems having different heat transfer resistances. With this in mind, the same model that was used for the integrated PCM evaporator system was used with the exception that the mass of PCM was not limited by eq. (14). The mass of the PCM for the remote system was chosen such that there was sufficient PCM mass to meet the entire peak cooling load. The fraction of total heat transfer that goes to single phase heat transfer $\left(f_{1 \phi}\right)$ and the $r_{\mathrm{o}}$ were used to account for the difference between a system that used a slurry PCM with direct contact heat exchange $\left(f_{1 \phi}=0.01\right.$ and $\left.r_{\mathrm{o}}=6.47 \mathrm{~mm}\right)$ and one that used additional heat exchangers with an additional heat transfer fluid $\left(f_{1 \phi}=0.08\right.$ or larger and $r_{\mathrm{o}}=10.0 \mathrm{~mm}$ or larger). The $r_{\mathrm{o}}$ was used to set the distance between the PCM phase boundary and the heat transfer surface. For example, a remote storage with a larger heat transfer surface area, would have a smaller effective $r_{\mathrm{o}}$, for a fixed PCM mass, than one with less heat transfer surface area. In this way, the system with the least heat transfer resistance (direct contact heat exchange between the refrigerant and PCM with a PCM slurry being pumped through the air-heat exchanger) was effectively compared to systems with larger heat transfer resistances that use secondary fluids and heat exchangers between the PCM and the air and the PCM and the refrigerant.

Figure 20 shows the system work for the remote PCM for various heat transfer resistances as represented by $f_{1 \phi}$ and $r_{\mathrm{o}}$ for two values of $K$ where a linear fit of the predictions is shown as a solid line. The required system work for the 1 ton system with remote PCM is between roughly 13200 $\mathrm{Wh}$ and $18550 \mathrm{Wh}$, which is roughly a $33 \%$ and a $6 \%$ reduction, respectively, in the required system energy of the 2 ton base case. Figure 20 shows that the required system work increases linearly as the fraction of the total heat transfer that goes to single phase heat transfer increases. For example, increasing $f_{1 \phi}$ from $1 \%$ to $25 \%$ causes a corresponding $24 \%$ and $27 \%$ increase in the required work for $K=0.722$ and $K=1.696$, respectively. Consequently, designing a system so that most of the energy is stored as phase-change energy with little subcooling of the PCM is crucial for an efficient energy storage design. For $f_{1 \phi}=1 \%$, the remote PCM system required approximately $24 \%$ and $33 \%$ less system energy than that required for the 2 ton compressor base case $(19632 \mathrm{Wh})$, for $K=0.722$ and $K=1.696$, respectively. For $f_{1 \phi}=25 \%$, the remote PCM system required approximately $6 \%(K=0.722)$ and $14 \%(K=1.696)$ less system energy than that required for the base case. As Fig. 20 shows, the average reduction for the $K=0.722$ and the $K=1.696$ systems was $15 \%$ and $24 \%$, respectively. 
Figure 20 shows that the variation in the value of $r_{\mathrm{o}}$ causes a $5 \%$ or less variation in the required system work. For the remote storage analysis, the $r_{\mathrm{o}}$ does not represent a physical diameter. Rather $r_{\mathrm{o}}$ approximates a region of influence for the PCM heat flux, which works to increase the surface temperature of the air-heat exchanger (Fig. 19) during cooling and to reduce the total cooling capacity. Figure 21 shows that less moisture removal occurs for the largest $r_{\mathrm{o}}$ and the largest $f_{1 \phi}$ as a result of the higher evaporator surface temperatures. However, Fig. 21 shows that the humidity ratio mainly remains within the acceptable thermal comfort region of less than 0.012 for the peak load hours. Consequently, care should be taken to ensure efficient heat exchange between the air and the PCM so that adequate de-humidification is attained.

\section{CONCLUSIONS}

The successful marriage of a PCM with a vapor compression cycle has the potential to significantly increase the efficiency of air-source vapor compression systems used for space conditioning, which relies on a favorable system design. To investigate the efficacy of certain residential energy storage designs, the air-conditioning performance, and the associated external and internal heat loads to NIST's Net-Zero Energy Residential Test Facility, were modelled for a single day near the summer. Two types of residential air-conditioning systems were examined to determine the energy savings and the peak load shifting that could be obtained by using PCM. The first type of system limited the mass of the PCM to minimize the required changes to a conventional cooling system. The main component of the first type of cooling system was the integrated PCM evaporator where a limited amount of PCM was placed directly integral to the tube of the evaporator within an annulus. The system with the integral PCM evaporator showed no potential advantage over a conventional system without PCM but with a larger evaporator and a smaller compressor. The system with the integral PCM evaporator failed to deliver energy savings and peak load shifting due to insufficient PCM and heat transfer resistance through the PCM held within the annulus. In contrast, the second type of residential cooling system, which used remotely stored PCM, exhibited significant energy savings while shifting the entire peak load to PCM heat exchanger with minimal electricity use during the peak load hours. In addition, the remote PCM system achieved between a $6 \%$ and a $33 \%$ reduction in the required energy for the entire cooling day, while maintaining acceptable indoor humidity ratios. The performance was best when the heat transfer resistance was minimized with direct contact heat exchange between the PCM and the evaporating refrigerant.

\section{ACKNOWLEDGEMENTS}

This work was funded by NIST. Thanks go to Dr. Riccardo Brignoli of the University of Padova and to Brian Dougherty and Piotr Domanski of NIST for their constructive criticism of the draft manuscript. 


\section{NOMENCLATURE}

English symbols

$A \quad$ heat transfer surface area $\left(\mathrm{m}^{-2}\right)$

$B_{\mathrm{n}} \quad$ fitting constants; $\mathrm{n}=0$ or $1(-)$

$c_{\text {pa }} \quad$ specific heat of moist air inside house $\left(\mathrm{kJ} \cdot \mathrm{kg}^{-1} \cdot \mathrm{K}^{-1}\right)$

$E_{\mathrm{ST}} \quad$ energy stored in the air (W)

$f_{1 \phi} \quad$ fraction of total load that is single-phase heat transfer (-)

$f_{\mathrm{p}} \quad$ fraction of total PCM mass that is frozen in annulus (-)

$h \quad$ heat transfer coefficient $\left(\mathrm{W} \cdot \mathrm{m}^{-2} \cdot \mathrm{K}^{-1}\right)$

$h A \quad$ heat conductance $\left(\mathrm{W} \cdot \mathrm{K}^{-1}\right)$

$i_{\mathrm{fg}} \quad$ latent heat of vaporization of water $\left(\mathrm{kJ} \cdot \mathrm{kg}^{-1}\right)$

$I_{\mathrm{s}} \quad$ solar irradiance $\left(\mathrm{W} \cdot \mathrm{m}^{-2}\right)$

$k_{\mathrm{p}} \quad$ thermal conductivity of $\mathrm{PCM}\left(\mathrm{W} \cdot \mathrm{m}^{-1} \cdot \mathrm{K}^{-1}\right)$

$K \quad$ system efficiency constant in eq. (20) (-)

$L_{\mathrm{e}} \quad$ total length of heat exchanger tubing (m)

$M \quad$ mass $(\mathrm{kg})$

$M_{\mathrm{a}} \quad$ total mass of dry air inside house $(\mathrm{kg})$

$n_{\mathrm{c}} \quad$ number of cycles

$N \quad$ nominal number of compressor tons (-)

$P \quad$ pressure $(\mathrm{Pa})$

$r \quad$ radial coordinate for tube with center origin (m)

$r_{\mathrm{i}} \quad$ inner tube annulus radius $(\mathrm{m})$

$r_{\mathrm{o}} \quad$ outer tube radius $(\mathrm{m})$

$t \quad$ time (s)

$t_{\mathrm{c}} \quad$ compressor run time (s)

$t_{\mathrm{t}} \quad$ PCM time to total thaw (s)

$T$ temperature (K)

$T_{\mathrm{a}} \quad$ air temperature $(\mathrm{K})$

$T_{\mathrm{pe}} \quad$ PCM phase-change temperature (K)

$T_{\mathrm{st}} \quad$ setpoint temperature of the thermostat $(\mathrm{K})$

$T_{\infty} \quad$ outdoor temperature (K)

$q_{\mathrm{e}} \quad$ evaporator heat duty (W)

$q_{\mathrm{ec}} \quad$ evaporator heat duty reduced by PCM resistance (W)

$q_{\mathrm{g}} \quad$ plug load for the house (W)

$q_{1} \quad$ evaporator air-side latent load (W)

$q_{\mathrm{p}} \quad$ total PCM evaporator duty (W)

$q_{\mathrm{pl}} \quad$ PCM evaporator latent duty (W)

$q_{\mathrm{ps}} \quad$ PCM evaporator sensible duty (W)

$q_{\mathrm{s}} \quad$ heat transfer from sun to house (W)

$q_{\mathrm{UA}} \quad$ heat transfer through walls driven by $T_{\infty}-T_{\mathrm{ai}}(\mathrm{W})$

$q_{\mathrm{o}}^{\prime \prime} \quad$ heat flux to outer tube $\left(\mathrm{W} \cdot \mathrm{m}^{-2}\right)$

Ste Stefan number, $\frac{c_{\mathrm{p}} q_{\mathrm{o}} r_{\mathrm{o}}}{k \lambda}(-)$

$U A \quad$ overall conductance of house exterior thermal envelope, walls, roof and windows $\left(\mathrm{W} \cdot \mathrm{K}^{-1}\right)$

$w \quad$ humidity ratio ( $\mathrm{kg}$ water vapor/ $\mathrm{kg}$ dry air)

$W \quad$ electrical work (W) 
$\underline{\text { Greek symbols }}$

$\triangle P \quad$ pressure drop $(\mathrm{kPa})$

$\Delta T_{\mathrm{p}} \quad$ temperature drop across the PCM annulus (K)

$\lambda_{\mathrm{p}} \quad$ latent heat of melting $\left(\mathrm{J} \cdot \mathrm{kg}^{-1}\right)$

$\eta \quad$ dimensionless radius; $\eta=r / r_{\mathrm{o}}(-)$

$\rho_{\mathrm{p}} \quad \mathrm{PCM}$ solid density $\left(\mathrm{kg} \cdot \mathrm{m}^{-3}\right)$

$\tau \quad$ time constant $\left(\mathrm{s}^{-1}\right)$

$\phi \quad$ indoor relative humidity (-)

$\omega \quad$ frequency $\left(\mathrm{s}^{-1}\right)$

\section{$\underline{\text { Subscripts }}$}

$1 \phi \quad$ sensible load

$2 \phi \quad$ latent load

c outdoor unit and indoor fan, cycle

d dew point

e evaporator

f fan

i indoor

I improved

$\mathrm{m}$ measured, maximum

n nominal

o outdoor, at outer tube wall

$\mathrm{p}$ predicted

PC phase change

$r$ house roof

s solar

W house wall

WN house window

$\underline{\text { Abbreviations }}$

\begin{tabular}{ll}
\hline AC & Air Conditioning \\
ASHP & air-source heat pump \\
COP & Coefficient of Performance \\
HRV & Heating Recovery Ventilator \\
NIST & National Institute of Standards and Technology (in U.S. Dept. of Commerce) \\
NZERTF & Net-Zero Energy Residential Test Facility at NIST \\
OD & Outer Diameter \\
PC & Phase Change \\
PCM & Phase-change Material \\
PV & Photovoltaic \\
SHGC & Solar Heat Gain Coefficient \\
TES & Thermal Energy Storage \\
U.S. & United States
\end{tabular}




\section{REFERENCES}

ASHRAE. 2017. ANSI/ASHRAE Standard 55-2017, Thermal Environmental Conditions for Human Occupancy.

ASHRAE. 2015. 2015 ASHRAE Handbook -HVAC Systems and Equipment, Chapter 51, Atlanta, GA, p. 51-1.

Baxter, V.D., and Moyers, J.C. 1985. Field-measured cycling, frosting, and defrosting losses for a high-efficiency air-source heat pump. ASHRAE Trans. Vol. 91:2B. 537-554.

Davis, M. W., Healy, W.M., Boyd, Ng., L, W. V., Payne, W.V. Skye, H., L., and Ullah, T. 2014. Monitoring Techniques for the Net-Zero Energy Residential Test Facility, NIST Technical Note 1854. U.S. Department of Commerce, Washington, D.C., http://dx.doi.org/10.6028/NIST.TN.1854

Incropera, F. P., and DeWitt, D. P. 2002. Fundamentals of Heat and Mass Transfer, 5th ed., John Wiley \& Sons, New York.

Clarksean, R. 2006. A phase change material slurry system to decrease peak air-conditioning loads, California Energy Commission, publication CEC-500-2006-026.

Kedzierski, M. A., Payne, W. V., and Skye, H. M. 2014. Potential Research Areas in Residential Energy Storage for NIST's Engineering Laboratory, NIST Technical Note 1844, U.S. Department of Commerce, Washington, D.C.

Kumano, H., Asaoka, T., and Sawada, S. 2014. Effect of Initial Aqueous Solution Concentration and Heating Conditions on Heat Transfer Characteristics of Ice Slurry, Int. J. Refrigeration, Vol. 41, pp. 72-81.

Lstiburek, J. W. 2010. The Perfect Wall, buildingscience.com, BSC: BSI-001, http://www.buildingscience.com/index_html.

Lo'pez-Navarro, A., Biosca-Taronger, J., Torregrosa-Jaime, B., Martı'nez-Galva', I.,Corbera' J. M., Esteban-Matı' J.C., and Paya', J. 2013. Experimental Investigation of the Temperatures and Performance of a Commercial Ice-Storage Tank, Int. J. Refrigeration, Vol. 36, pp. 1313-1318.

Omar, F. 2017. Private communications. National Institute of Standards and Technology. Gaithersburg, MD.

Omar, F., Bushby, S. T., and Williams, R. D. 2017. A self-learning algorithm for estimating solar heat gain and temperature changes in a single-family residence. Energy and Buildings. 150, 100110. http://dx.doi.org/10.1016/j.enbuild.2017.06.001

Park. Y. C., Kim, Y. C., and Min, M. 2001. Performance analysis on a multi-type inverter air conditioner, Energy Conversion and Management, 42, 1607-1621. 
Pettit, B., Gates, C. Fanney, A. H., and Healy, W. M. 2015. Design Challenges of the NIST Net Zero Energy Residential Test Facility. NIST Technical Note 1847, U.S. Department of Commerce, Washington, D.C. https://dx.doi.org/10.6028/NIST.TN.1847

Shamsundar, N., and Sparrow, E. M. 1974. Storage of Thermal Energy by Solid-Liquid Phase Change-Temperature Drop and Heat Flux, ASME J. Heat Transfer, 96(4):541-544. doi:10.1115/1.3450242. 


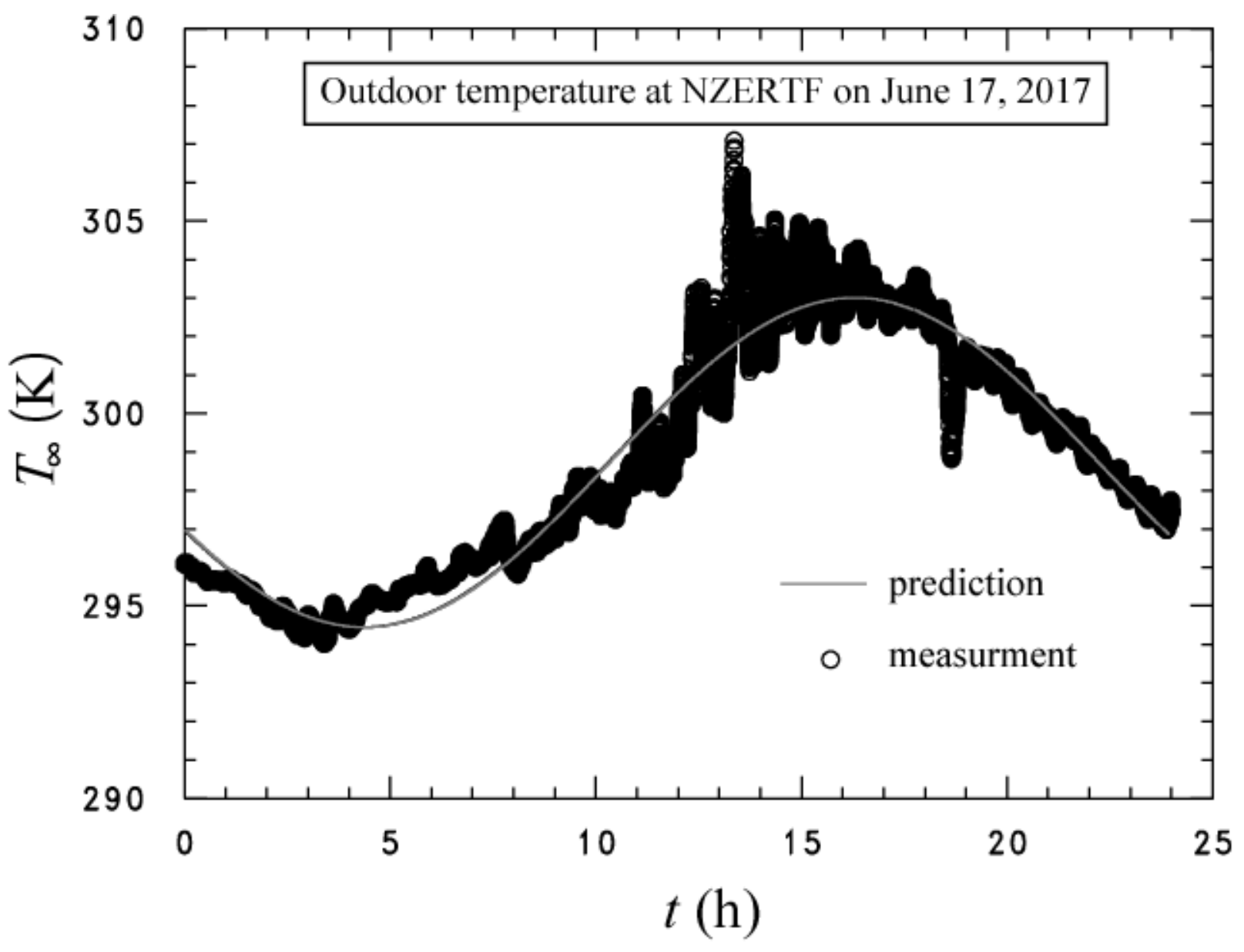

Figure 1 Outdoor temperature for June 17, 2017 


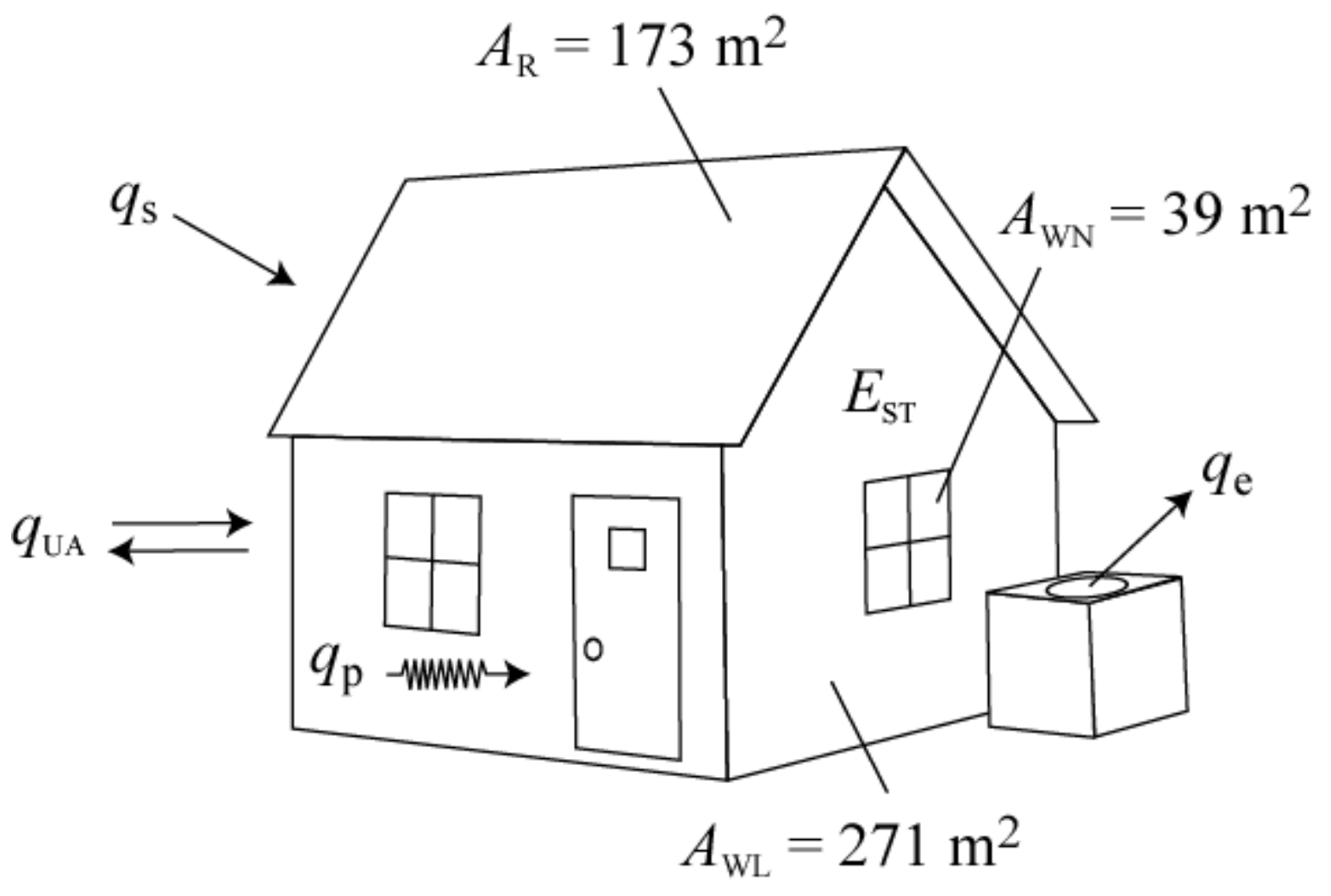

Figure 2 Energy balance for NZERTF 


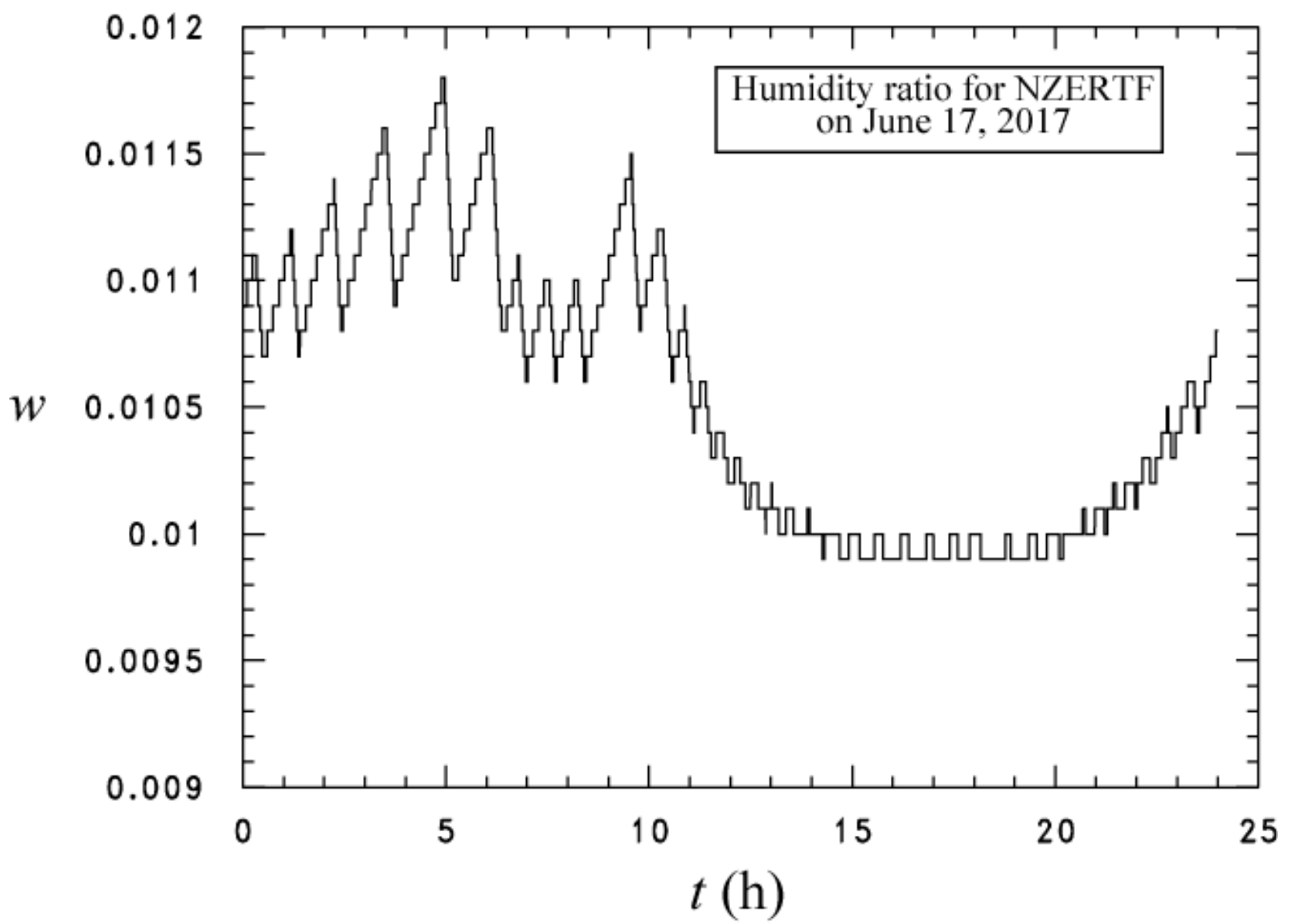

Figure 3 Humidity ratio for the NZERTF on June 17, 2017 


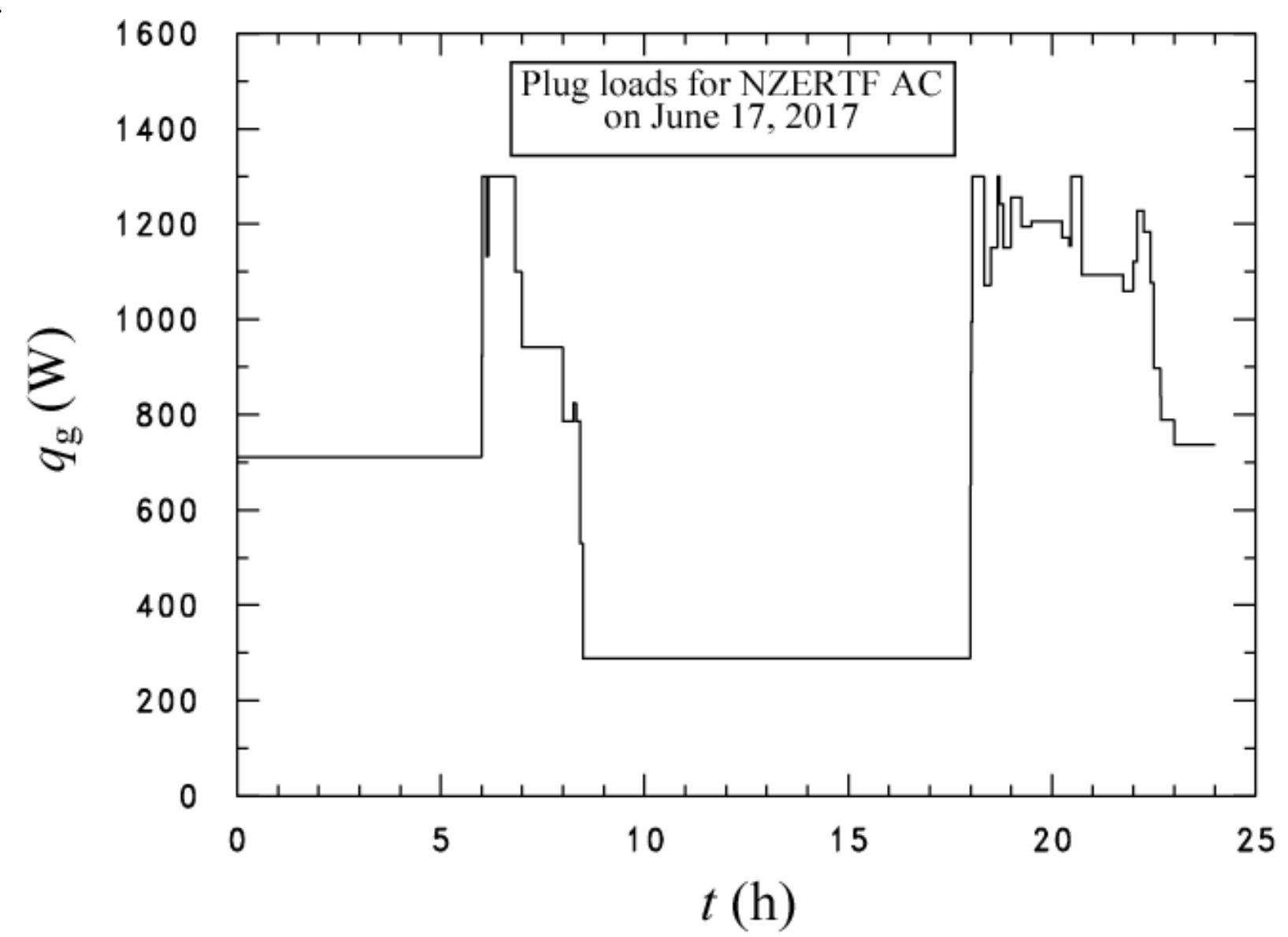

Figure 4 Plug loads for NZERTF on June 17, 2017 


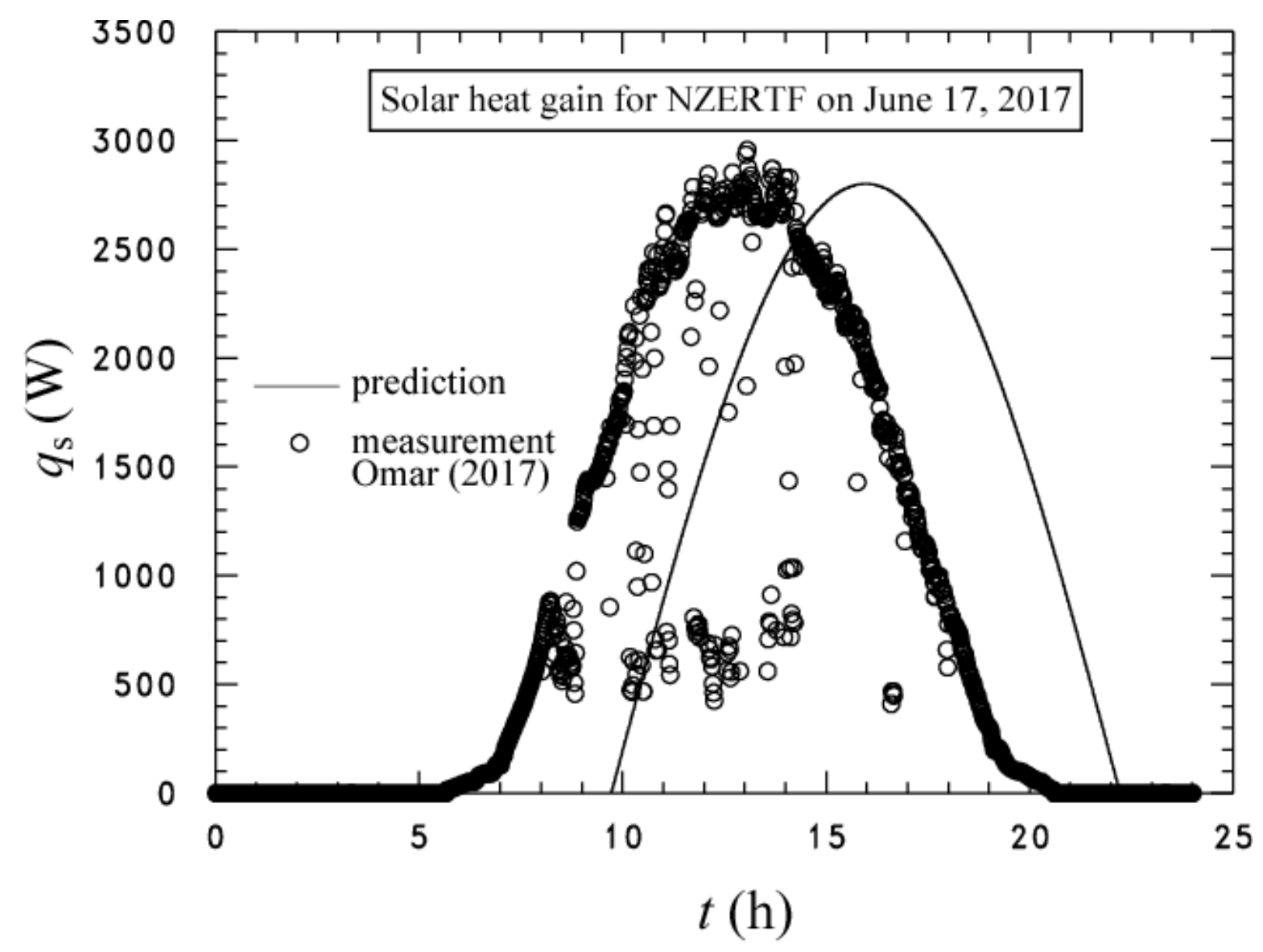

Figure 5 Solar heat gain on June 17, 2017 


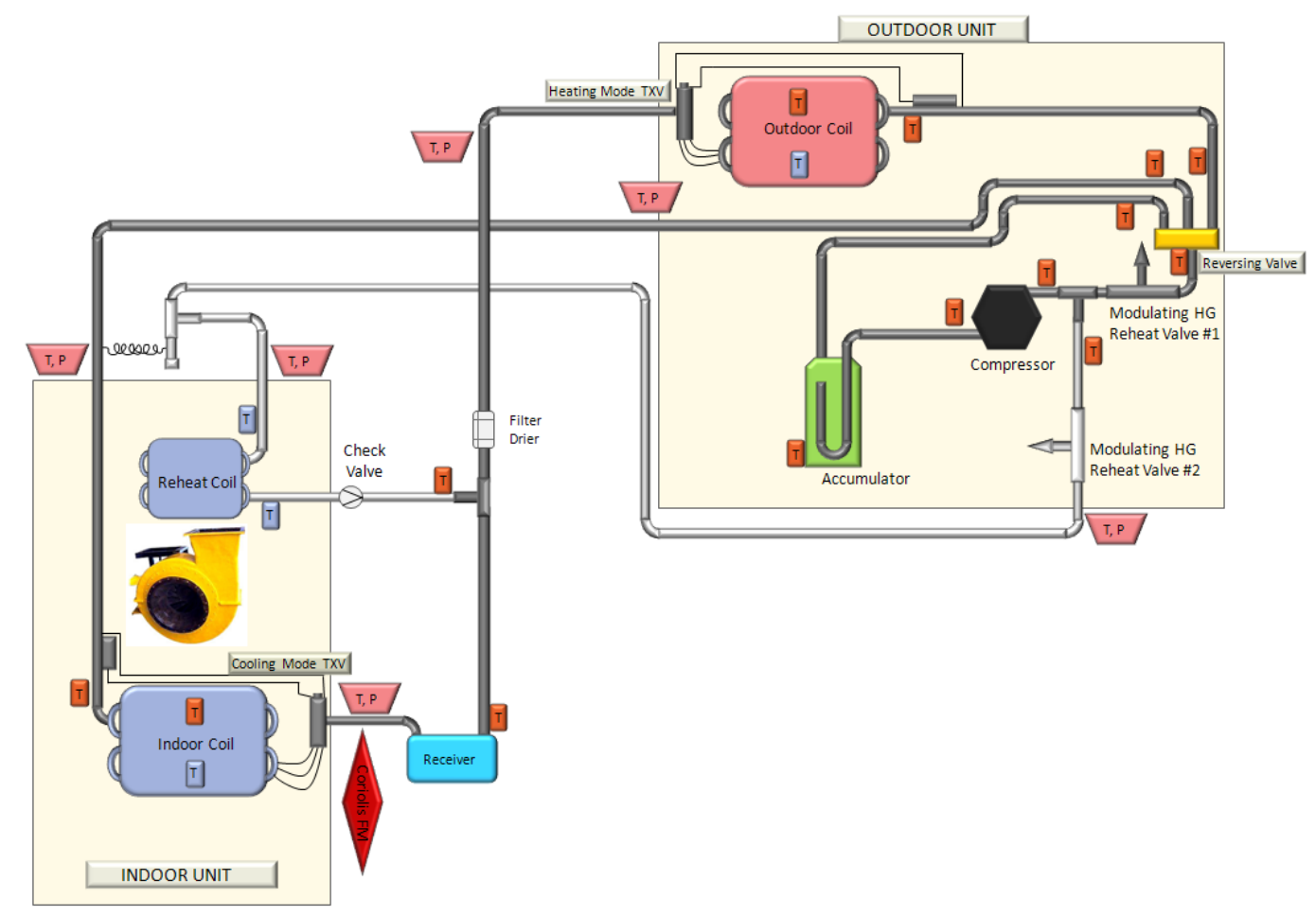

Figure 6 NZERTF air-source heat pump schematic (Davis et al., 2014) 


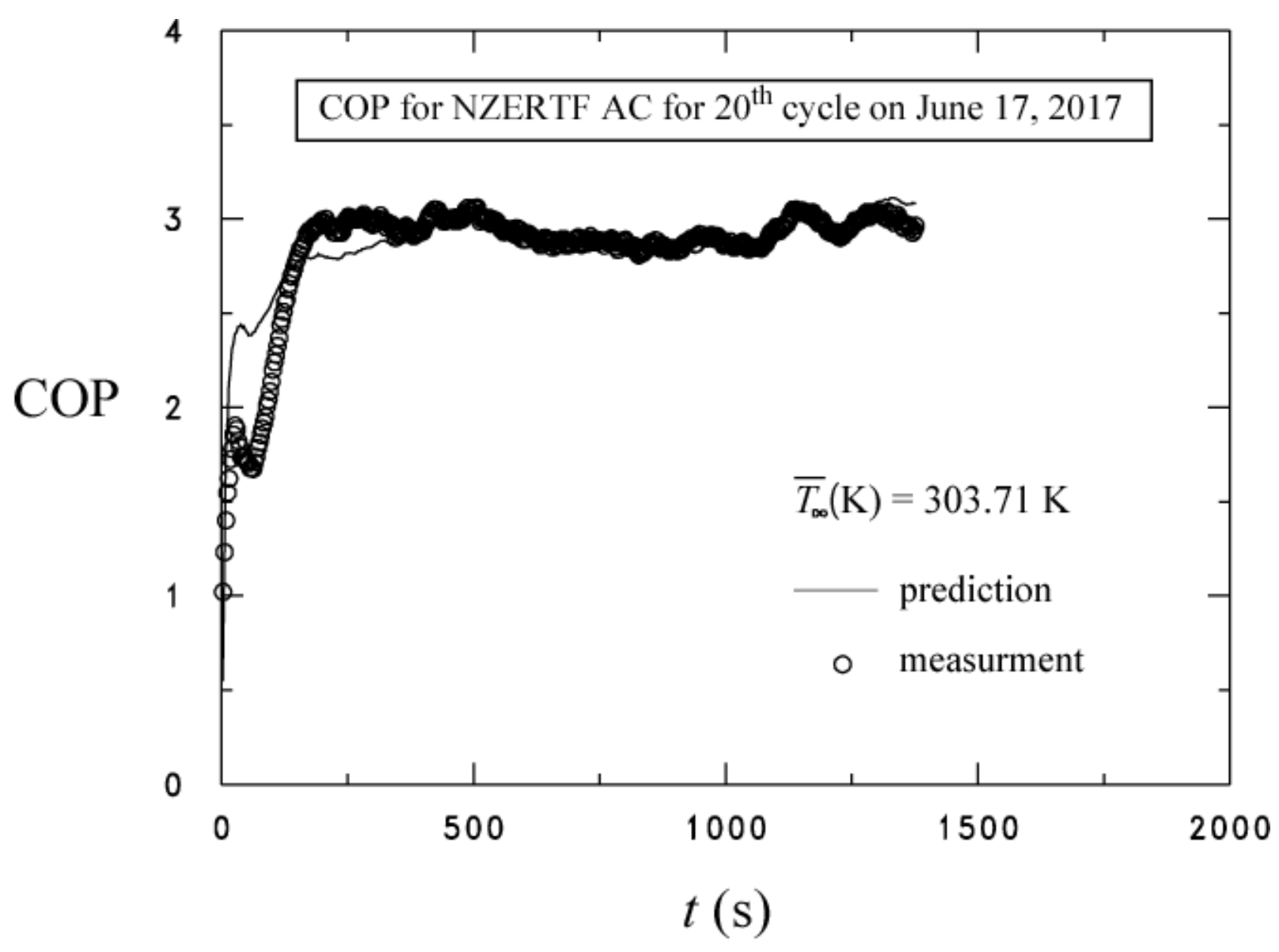

Figure 7 COP for $20^{\text {th }}$ cycle on June 17, 2017 


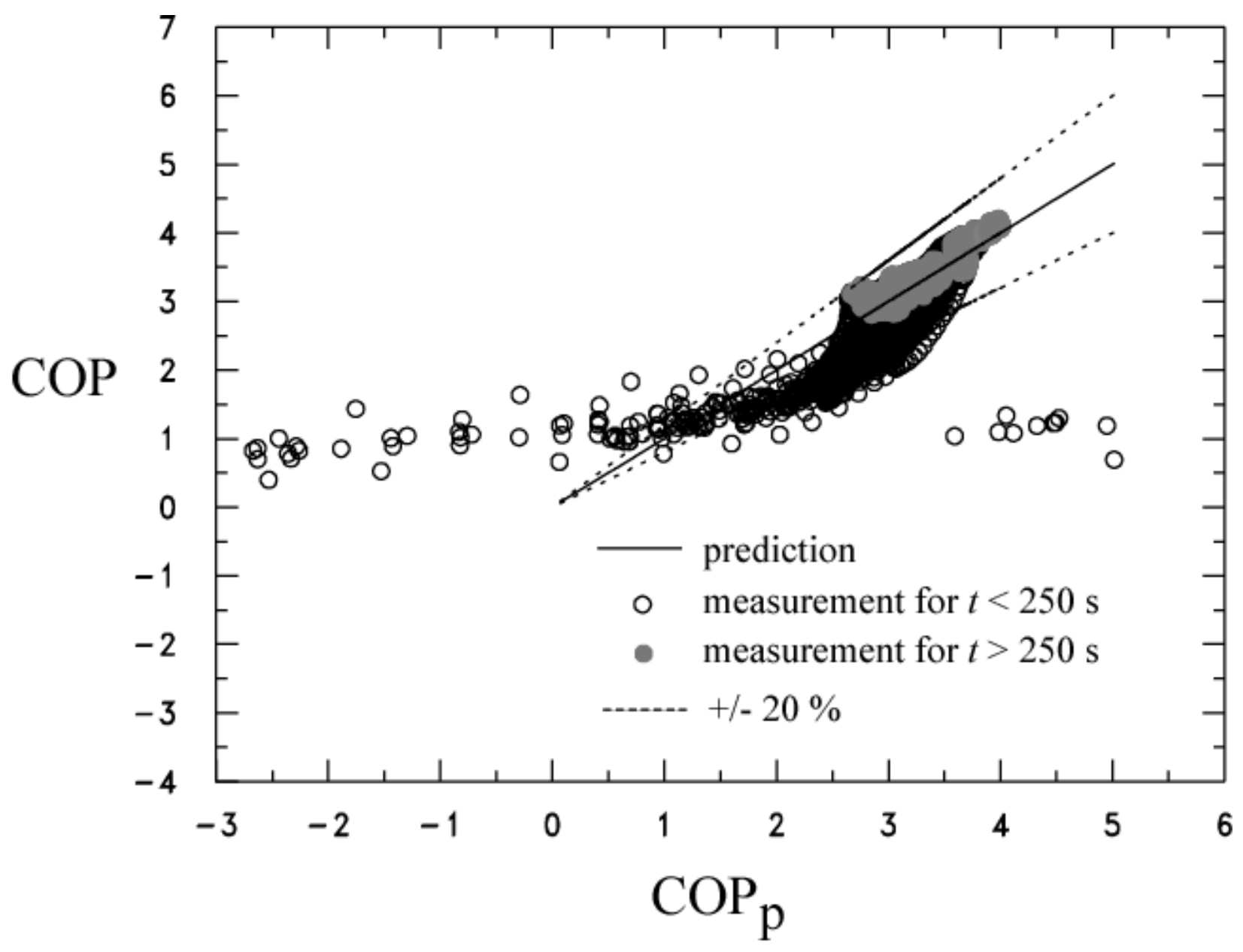

Figure 8 Comparison of measured COP to that predicted with eq. (3) for all 37 cycles 


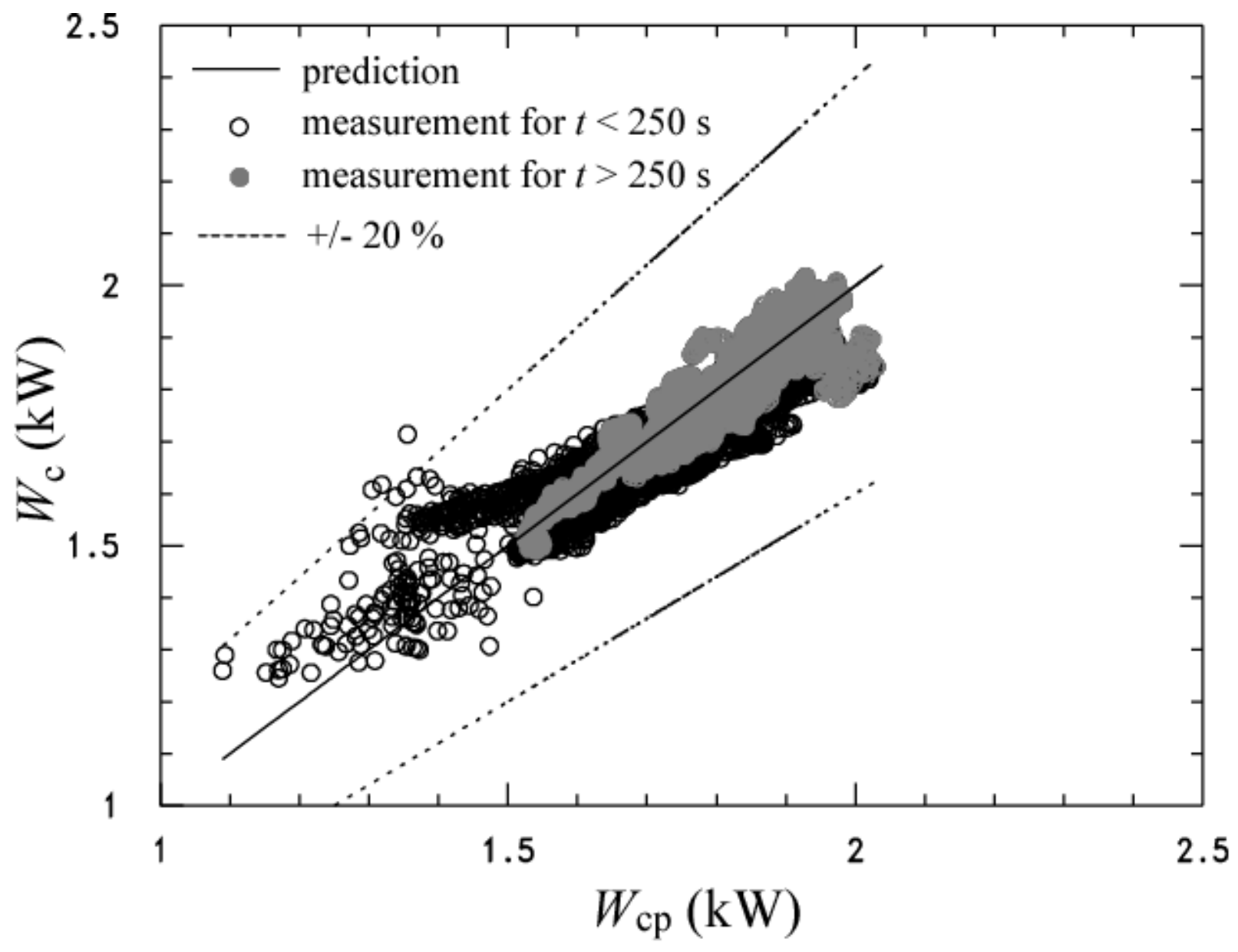

Figure 9 Comparison of measured total work to that predicted by eq. (11) for all 37 cycles 


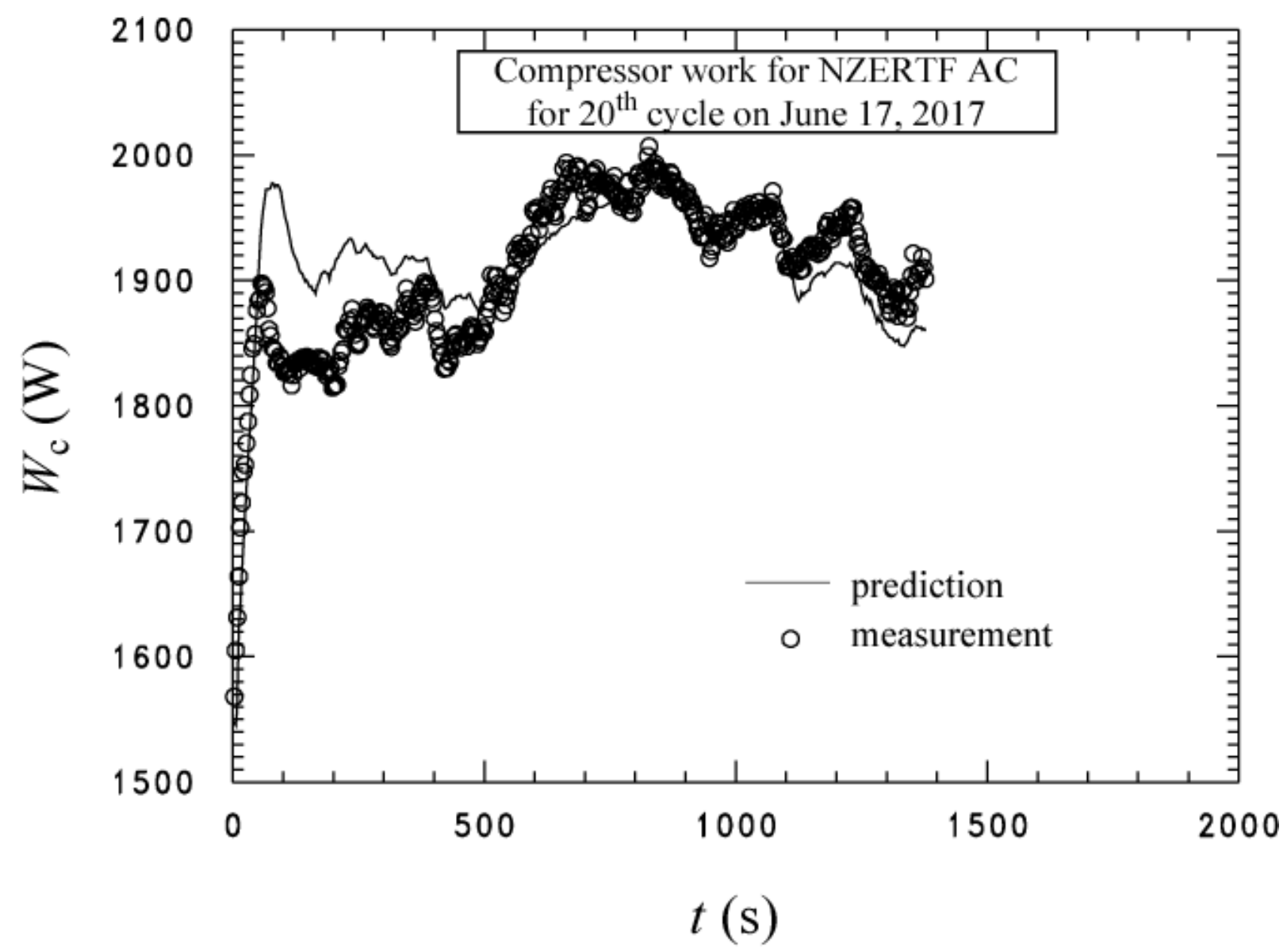

Figure 10 Comparison of measured compressor and fan work that predicted with eq. (11) for $20^{\text {th }}$ cycle on June 17,2017 


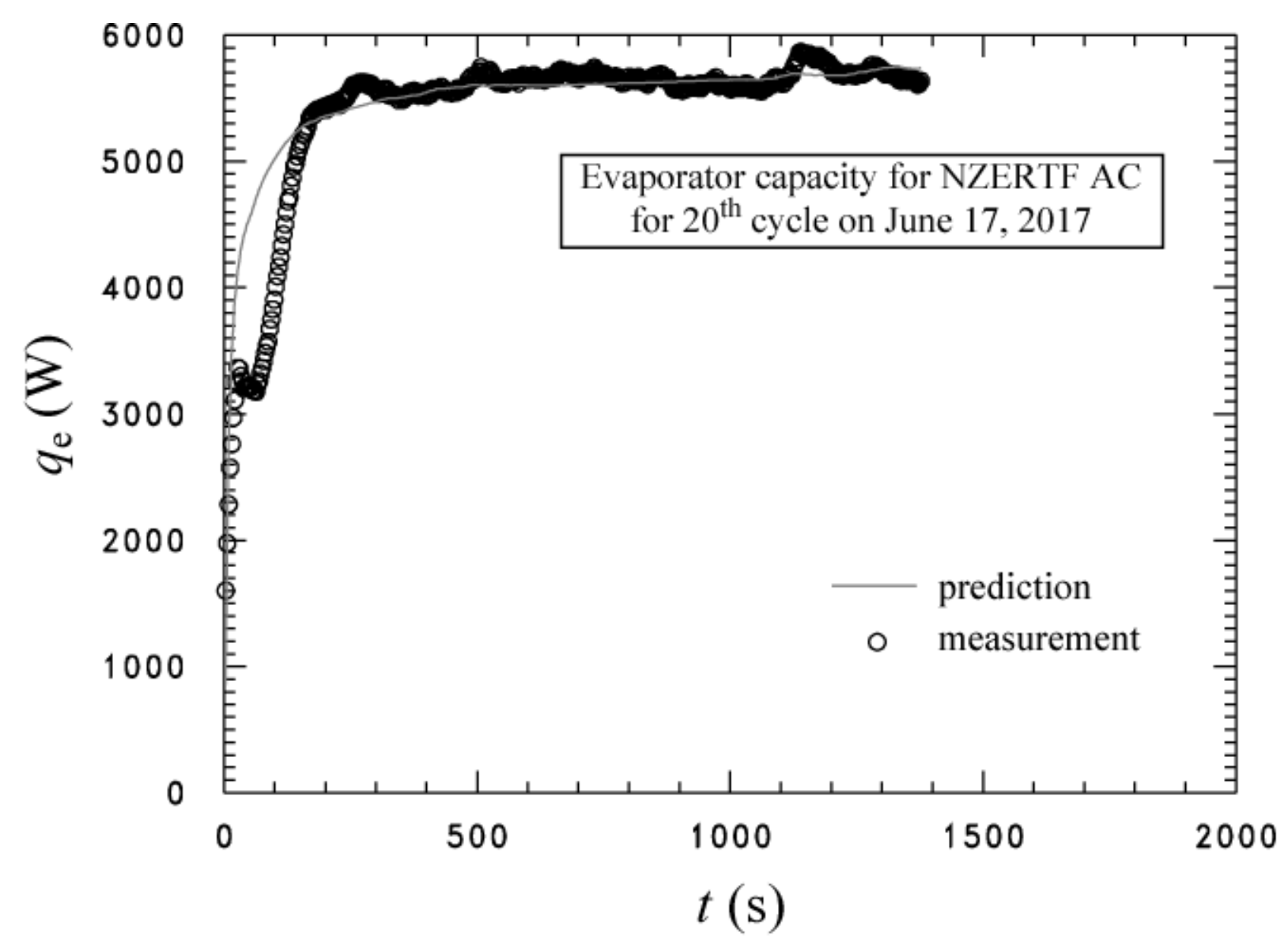

Figure 11 Comparison of measured evaporator capacity to that predicted with eq. (12) for $20^{\text {th }}$ cycle on June 17,2017 


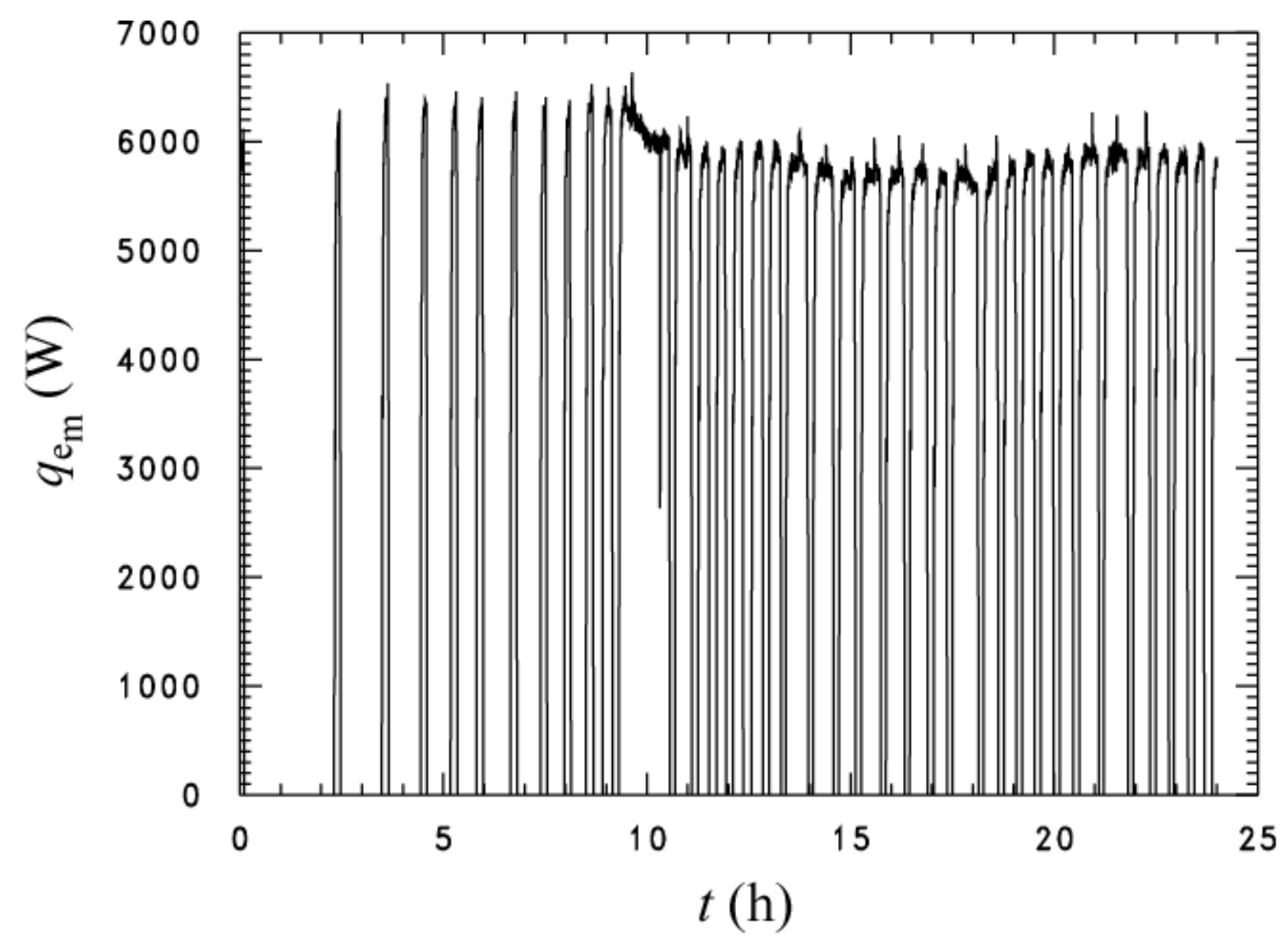

Figure 12 Measured evaporator capacity for all cycles of June 17, 2017 


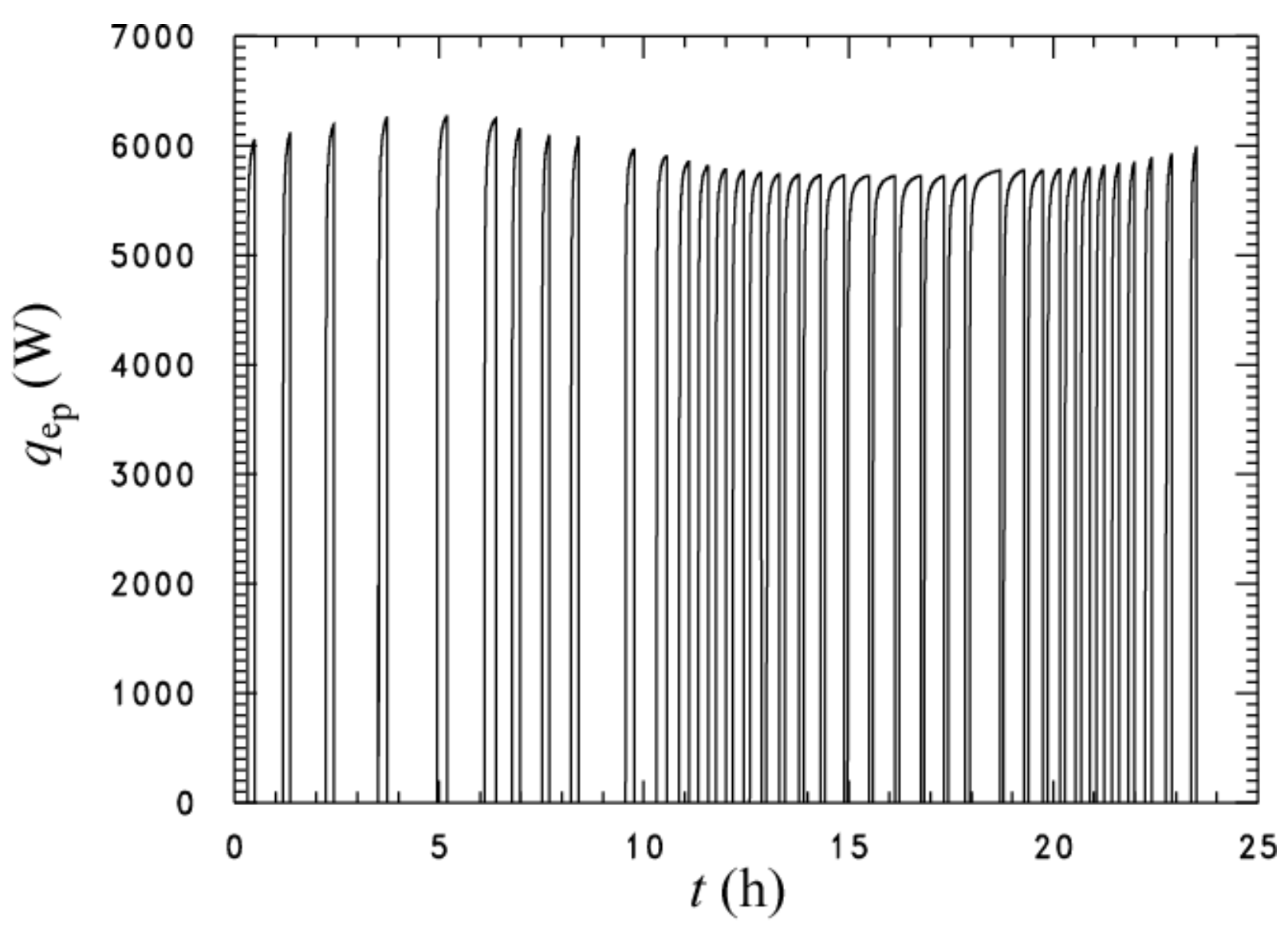

Figure 13 Predicted evaporator heat loads for all cycles of June 17, 2017 


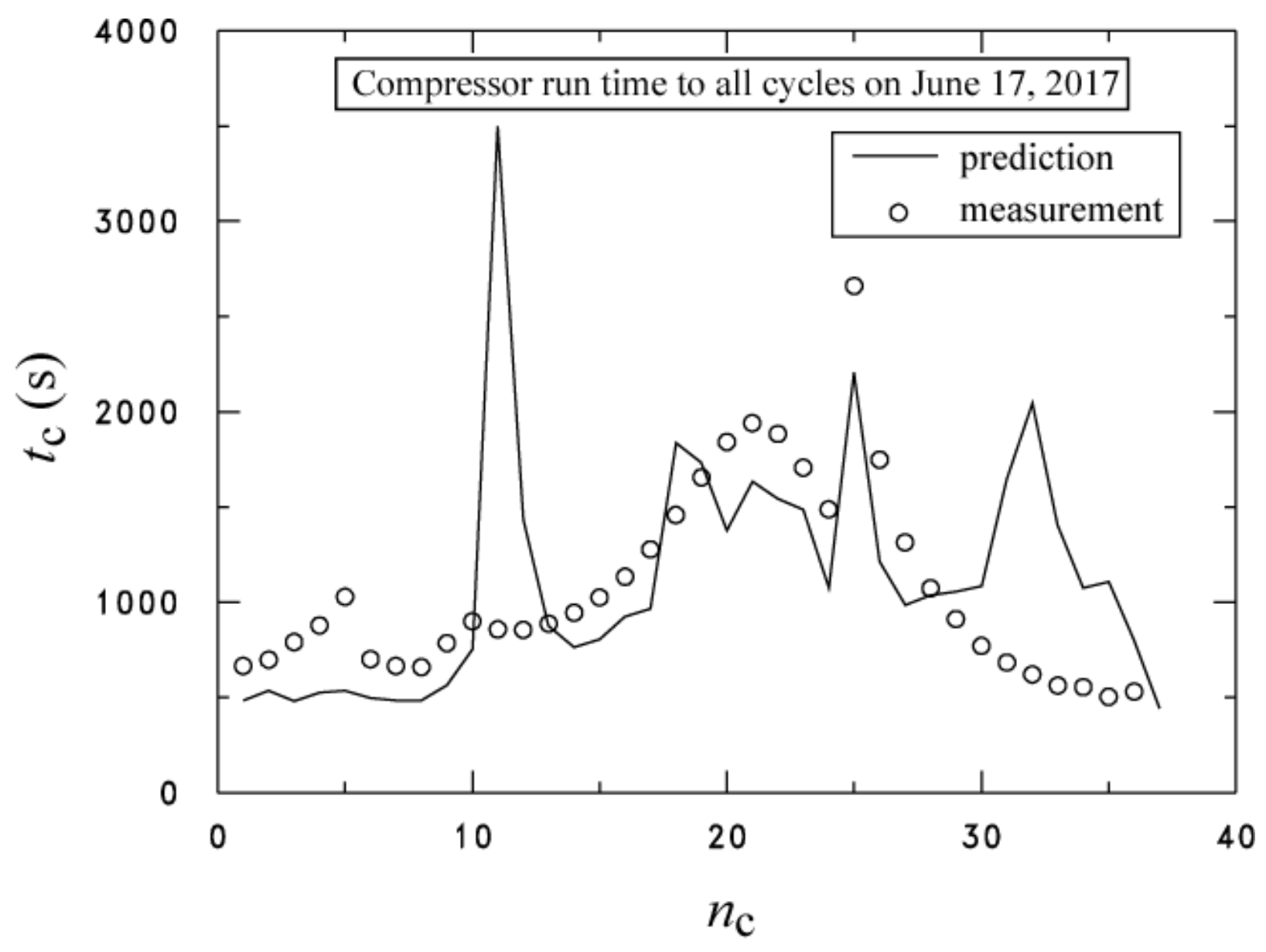

Figure 14 Comparison of measured to predicted compressor run time for all cycle of June 17, 2017 


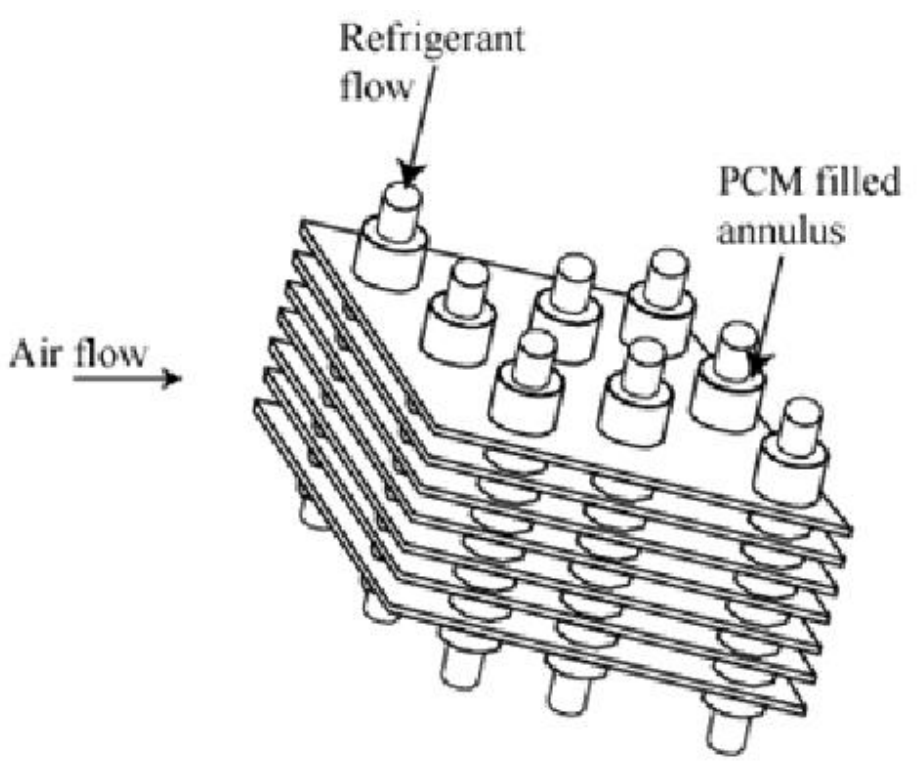

Figure 15 Proposed PCM evaporator for investigation (Kedzierski et al., 2014) 


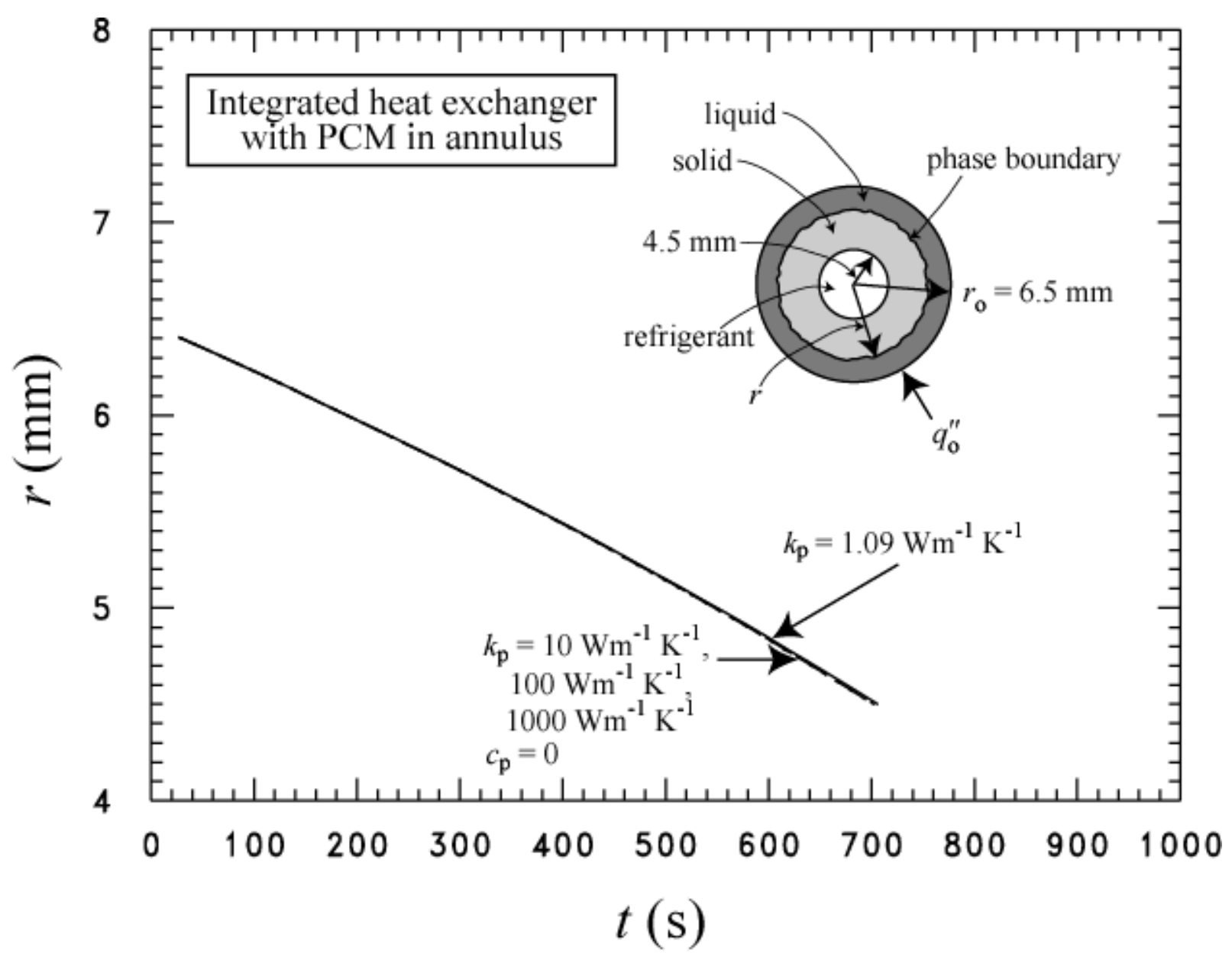

Figure 16 Shamsundar and Sparrow (1974) model for freezing and melting time for PCM 


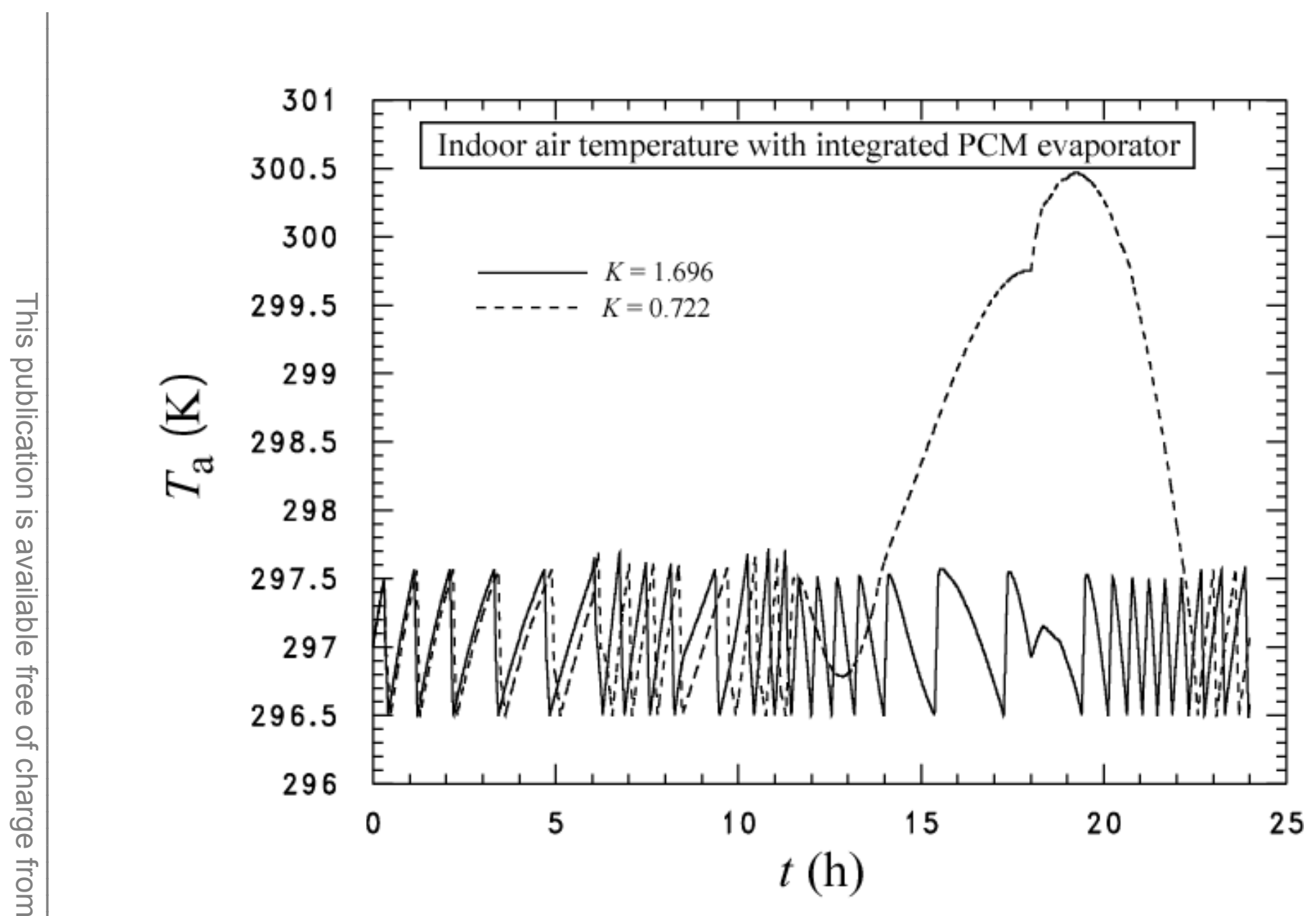

Figure 17 Indoor air temperature when using integrated PCM evaporator and 1 ton two-speed compressor 


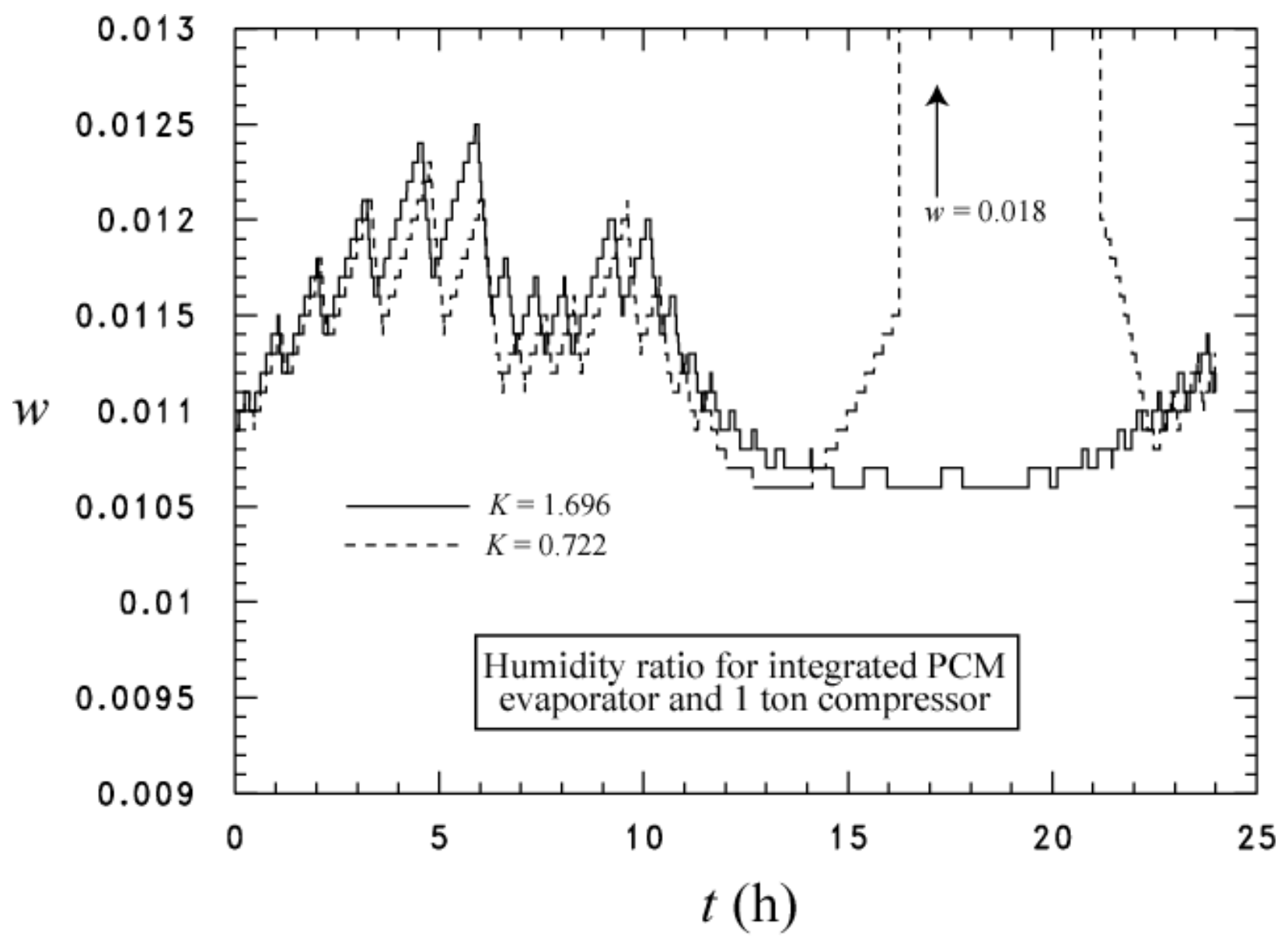

Figure 18 Indoor humidity ratio when using integrated PCM evaporator and 1 ton, two-speed compressor 


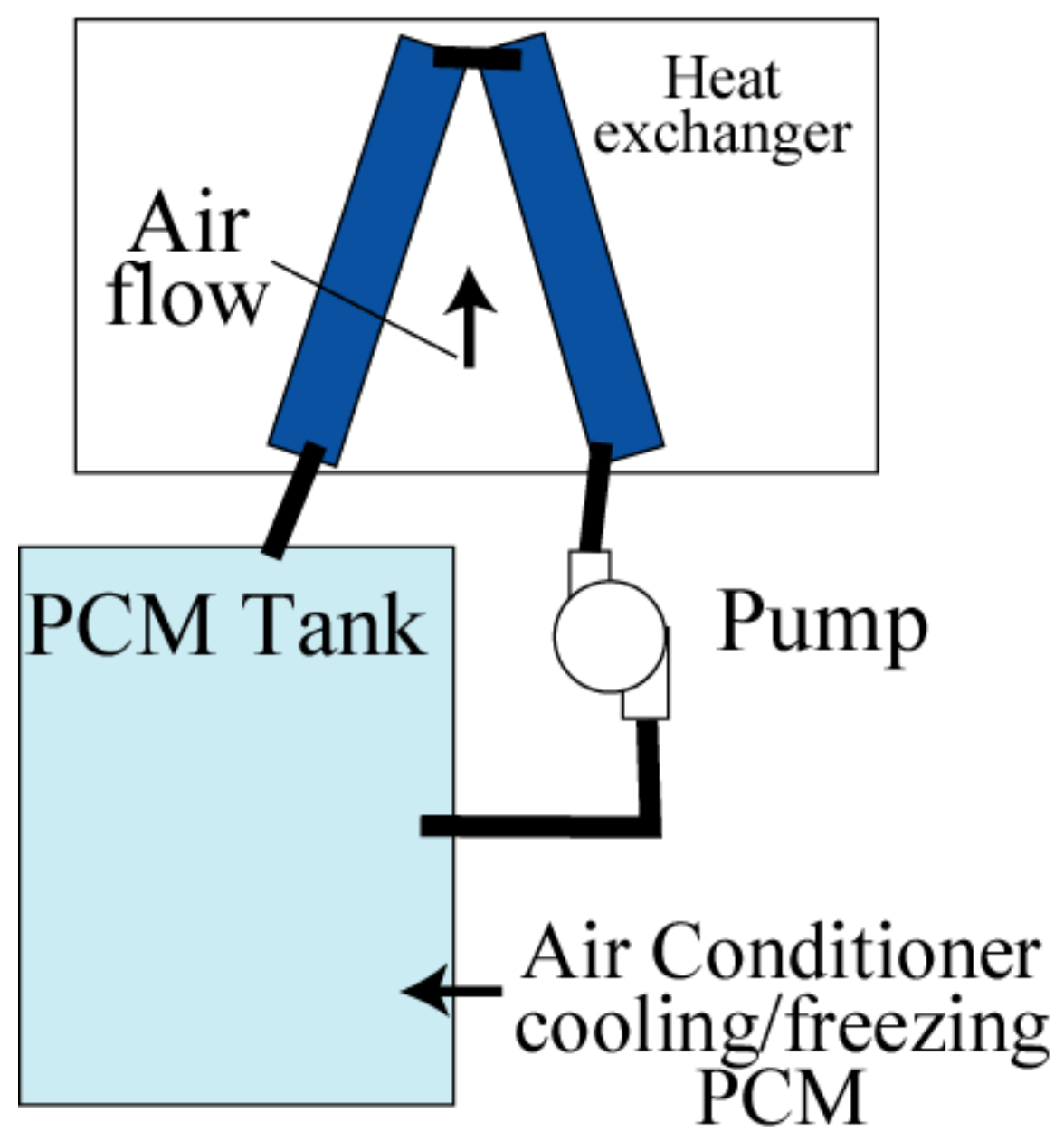

Figure 19 Schematic of remote PCM storage for residential air conditioning 


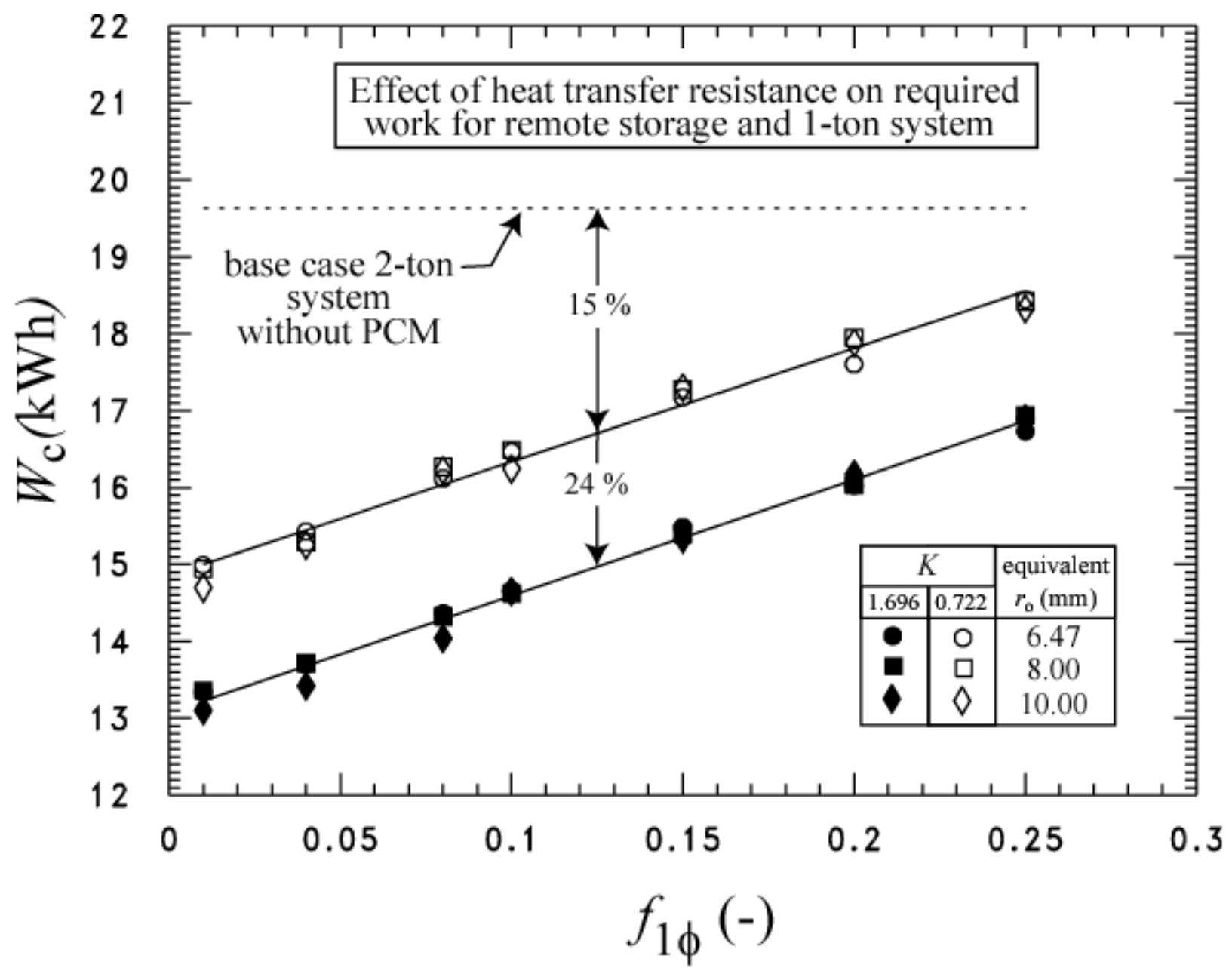

Figure 20 Effect of heat transfer resistance on required compressor and outdoor fan work for remote storage 


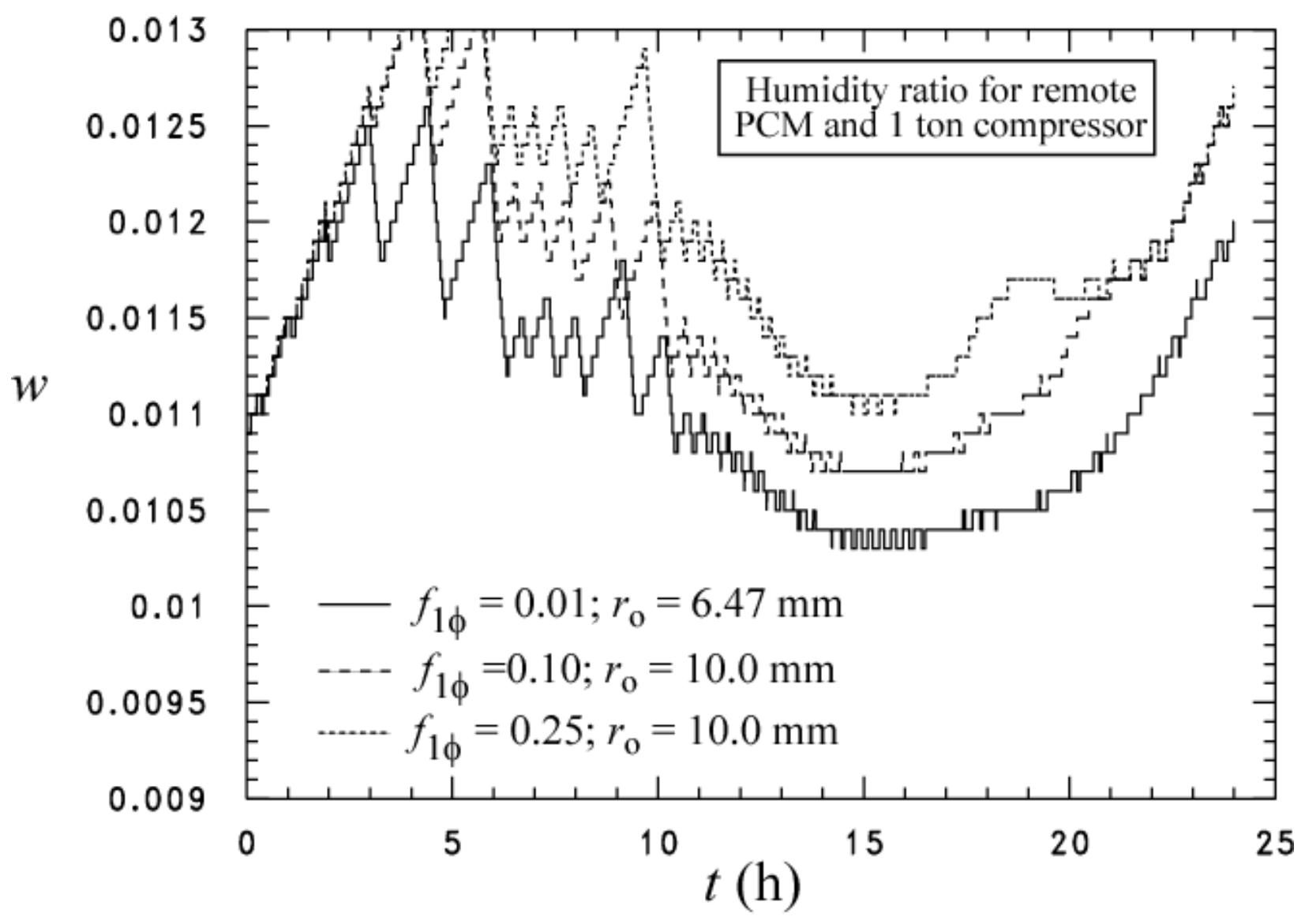

Figure 21 Effect of heat transfer resistance on indoor humidity ratio when using remote PCM and 1 ton compressor 